\title{
Anthropomorphic Objects
}

\author{
by \\ Ana Jofre \\ A thesis exhibition presented to OCAD University \\ in partial fulfillment of the requirements for the degree of \\ Master of Fine Arts \\ in
}

Interdisciplinary Master's in Arts Media and Design

Exhibition Details:

OnSite [at] OCADU,

230 Richmond St.

Toronto, Ontario, Canada

April 1-5, 2015

(C) Ana Jofre 2015 


\section{Author's Declaration}

I hereby declare that I am the sole author of this thesis. This is a true copy of the thesis, including any required final revisions, as accepted by my examiners.

I authorize OCAD University to lend this thesis to other institutions or individuals for the purpose of scholarly research.

I understand that my thesis may be made electronically available to the public.

I further authorize OCAD University to reproduce this thesis by photocopying or by other means, in total or in part, at the request of other institutions or individuals for the purpose of scholarly research. 


\section{Acknowledgements}

I would like to thank my primary advisor Dr. Barbara Rauch for her support and feedback throughout this work. I also thank Nick Puckett (my secondary advisor), Dr. Martha Ladly, and Amy Swartz for also providing helpful feedback throughout the process. 


\title{
Anthropomorphic Objects
}

\author{
Ana Jofre \\ MFA in Interdisciplinary Arts Media and Design at OCADU, 2015
}

\begin{abstract}
This thesis exhibition is the culmination of an exploration of the uncanny through sculptures that evoke the sensation of a living presence. Each sculpture is also intended to convey some character or personality, and to this end, my work is influenced by puppetry. Though the works are human sized, they function as puppets in that they are posable and can be used for performance, but they are also robotic in that they have some autonomous motion and some reactive motion. My sculptures are based on the human form because the human form is at once most uncanny and also most relatable. Relatability is an important aspect of my work, as I use my humanoid sculptures to create playful interactive experiences for viewers, experiences that hinge on the uncanny and the illusion of presence.
\end{abstract}

KEYWORDS: FIGURATIVE SCULPTURE, PUPPETS, AUTOMATONS, ROBOTS, ANDROIDS, UNCANNY, CAMP, PRAGMATIST AESTHETICS 


\section{Table of Contents}

PART 1: INTRODUCTION ............................................................. 1

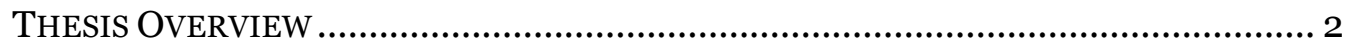

MOTIVATION AND CULTURAL CONTEXT …………………………………….... 4

THEORETICAL FRAMEWORK........................................................................... 6

Theme Of Investigation: The Uncanny ..................................................... 6

Pragmatist Aesthetics..................................................................................... 9

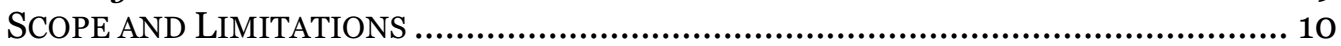

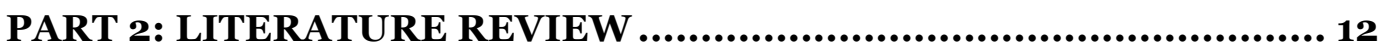

BRIEF LOOK AT CONTEMPORARY ROBOTIC ART...............................................12

THE VISUAL LANGUAGE OF THE HUMAN FIGURE .....................................................14

Some Case Studies in Sculpture ...................................................................14

Blurring the Boundaries between Art and Life............................................ 27

The Uncanny in figurative sculpture ...........................................................28

PUSHING THE ENVELOPE OF LIFELIKENESS: HUMANOID ROBOTS AND ANDROIDS 30

The Uncanny Valley ...................................................................................... 36

The Case in Favor of the Uncanny ................................................................41

Why, exactly, are androids uncanny?............................................................ 43

PUPPETRY: THE ART OF THE UNCANNY .............................................................. 46

LITERATURE REVIEW SUMMARY .................................................................... 53

PART 3: GOALS, METHODOLOGY, AND SENSIBILITY ....................54

PROJECT OBJECTIVES AND RESEARCH QUESTIONS ................................................ 54

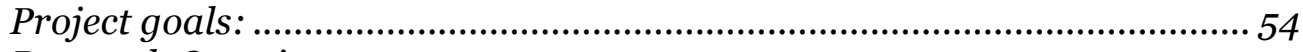

Research Questions: ........................................................................................ 54

METHODOLOGY ……………………………………………………………. 55

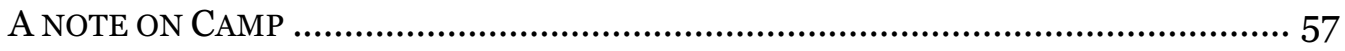

PART 4: RESULTS AND OUTCOMES ............................................63

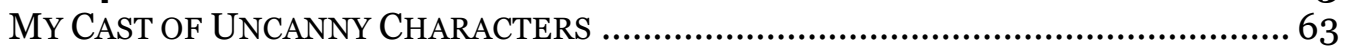

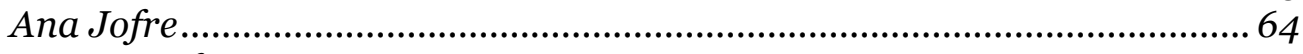

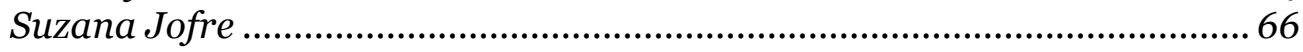

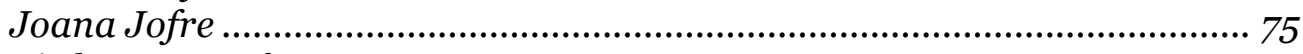

Little Beast Jofre ........................................................................................... 86

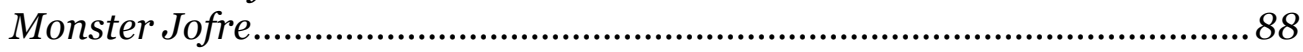

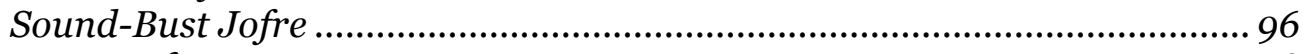

Fuzzy Jofre ..................................................................................... 98

SUMMARY OF PROCESSES ............................................................................. 100

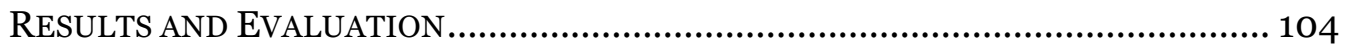

PART 4: CONCLUSIONS .................................................................. 104

POSSIBLE FUTURE DIRECTIONS....................................................................... 104

SUMMARY AND CONCLUSIONS..........................................................................116

BIBLIOGRAPHY AND WORKS CITED ........................................119 


\section{List of Figures}

FIGURE 1: THE UNCANNY VALLEY (MORI 1970)...................................................................... 37

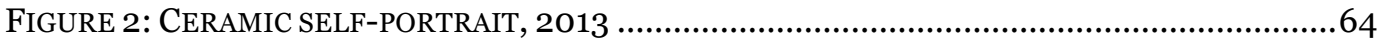

FigURE 3: SUZANA JOFRE (2013) (PHOTOGRAPH 2014 BY KRIS BRANDHAGEN) .........................69

FIGURE 4: PERFORMING WITH SUZANA (2014) ……….......................................................70

Figure 5: SMOKING SUZANA (2013) (PhOTOGRAPHY BY AdRIAN PhILliPS) ...............................72

Figure 6: SuZANA, ANA, AND ANA (2013) (PHOTOGRAPHY BY AdRIAN PHILLIPS) .................... 73

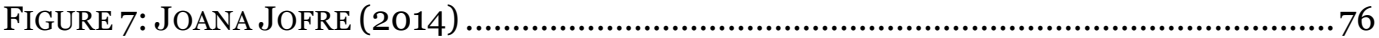

FIGURE 8: PILAR TAKING A SELFIES WITH JOANA (LEFT) AND SUZANA (RIGHT) (2014)...............78

FIGURE 9: PILAR AND THE PAPPARATZI (2014) ………............................................................78

FiguRE 10: JOANA JOFRE AT THE GLADSTONE HOTEL CAFE (JANUARY 2014) .......................... 80

FIGURE 11: VIEWER AT GRANGE PARK TAKES A SELFIE WITH JOANA (2014) (PHOTOGRAPHY BY

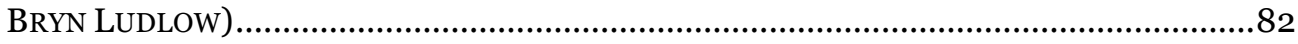

FIGURE 12: VIEWER AT GRANGE PARK ENGAGES JOANA IN CONVERSATION (2014)

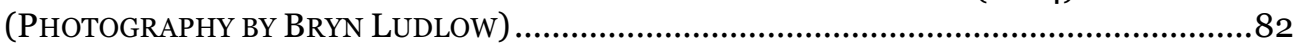

FiguRE 13: JOANA WITH SUZANA (STILL FROM 'THE LONG WALK HOME' 2014).......................84

FIGURE 14: JOANA HAND TAP (2014) (PHOTOGRAPHY BY JUAN BONILLA) ................................86

FIGURE 15: VIEWER PETTING THE LITTLE FURRY BEAST (2014) ............................................8 87

FIGURE 16: LEFT - CNC CARVED PARTS, RIGHT - ASSEMBLED FIGURE ..................................... 90

FIGURE 17: INTERMEDIATE FORM (LATER TO BECOME MONSTER JOFRE) (2014) .......................93

Figure 18: ME AND MONSTER JOFRE (2014) PHOTOGRAPHY: JUAN BONILLA ...........................94

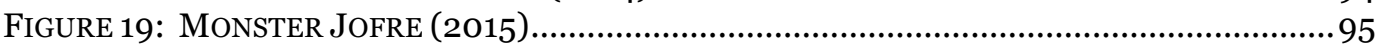

FIGURE 20: SOUND-BUST JOFRE (2014) ...........................................................................98

FIGURE 21: LEFT - SELF PORTRAIT. RIGHT - FACES COPIED SELF-PORTRAIT. ...........................100

FIGURE 22: FUZZY JOFRE (2015) .................................................................................100 


\section{PART 1: INTRODUCTION}

This project integrates knowledge and methodologies from sculpture, puppetry, and robotics to create aesthetic experiences of 'presence'. The artistic goal of this research is to create humanoid creatures, with human dimensions and some autonomous motion, which convey the illusion of a living presence, as well as personality and character. The intent is to instigate reflection on how we emotionally connect with lifelike objects within a cultural context in which robots (objects with presence) are starting to become commonplace across society. While my works are not exactly robotic, they have just enough motion and response to create a momentary illusion of life. In my investigation into how to create the illusion of lifelikeness, I found that this sensation is evoked by objects of human scale with anatomically correct proportions, by objects with autonomous motion, and by objects that mechanically respond to the viewer. I also explored how to convey personality and character, and found that while maintaining neutral facial expressions, I can convey personality through materiality, costumes, and (simple repetitive) behaviors. I position my artistic output somewhere between puppetry, an ancient art that relies on the illusion of a living presence as a means of expression, and figurative sculpture, which uses the visual language of the 
human body to create an experience of contemplation. In the process of creation, I review studies in robotics that reveal how to design lifelike creatures that communicate specific emotions, as well as studies that examine how humans interact with affective robots. My artistic output is further informed by documenting observations of the creation process and of viewer's interactions with the artworks. I found that I was able to create playful situations for those who encountered my creations. The work is grounded in John Dewey's pragmatist aesthetic theory (Dewey 1934), where the importance is neither on the art object itself nor in the emotional expression of the artist, but rather on the emotional experience the object creates and the social function it serves.

\section{Thesis Overview}

I explore methods by which to create objects that evoke the sensation of a living presence, and argue that such uncanny experiences of presence are evoked by objects that are humanoid in form and proportions, by objects that are placed within a narrative structure, by objects that move in lifelike ways, by objects that move autonomously, and by objects whose motion is responsive to the viewer. The question that informs my practice is: what visual elements contribute to creating the illusion that an object has a 
sentient identity? The illusion of sentience, particularly in anthropomorphic objects, often creates uncanny sensations. So, I also argue that uncanny experiences are an important subset of aesthetic experiences because such experiences challenge viewers to face their fears and deep-rooted assumptions, and may instigate thoughtful questioning of the human condition.

The literature review surveys practices that evoke the uncanny, that use the human figure, or that create the illusion of a living presence, and I examine how they function in society. I start with a look at figurative sculpture to provide examples of the use of the human figure as a means for universal expression and as a means for social criticism. Additionally, I review some of the history of puppetry to demonstrate its function in social criticism through its role in political protest and social movements. The art of puppetry also provides insight into how to invoke the illusion of life. I look at the cognitive science behind developments in robotics to gain more quantitative insight into how to create an object with life-like presence, and through a survey of humanoid robots, I reveal that the motivation for creating androids (human-like robots) is an extension of the drive to create figurative sculptures: to instigate reflection on the 
human condition. I also argue that uncanny human representation is a valuable element for critical reflection.

Following the literature review, I describe my methodologies and my sensibilities, and I outline my project objectives. The subsequent section explains the process each of the major works featured in the thesis exhibition. My practice outcomes are four life-sized full body characters, and a few smaller works. Only one of the life-sized characters is fully human in appearance; the others deviate from looking fully human in several ways, and with these deviations, I examine variations on the uncanny and on the sensation of presence. I include reflections on their creation and on viewer response to draw conclusions about which strategies and techniques are most effective in creating uncanny yet pleasurable experiences.

\section{Motivation and Cultural Context}

Uncanny experiences, in which one imagines life in an object, can be pleasurable or thought provoking. My artistic production intends to instigate reflection on the boundaries between subject and object within a contemporary cultural context in which objects are becoming increasingly 
personalized and personable. Humanoid robots are a naturally human extension to the creation of personable objects; at the time of this writing, the first financially accessible home robot, Jibo, has sold its first batch (Breazeal 2014). But humanoid robots that look actually human (in other words, androids) are still a longer way from everyday use, in part because of the uncanny, perhaps because facing a mechanistic entity that resembles us may uncomfortably remind us that we are (very complex and biological) machines.

The research undertaken in producing this artistic body of work speaks to the field of human-robot interactions, addressing the question of how an object can evoke a sense of presence and take on a personality. Presence and personality are traits that we attribute to biologically sentient beings, and uncanny feelings can occur when such traits are ascribed to inanimate objects. In a seminal paper from 1970, Roboticist Masahiro Mori defined the uncanny valley when considering humanoid robot design (Mori 1970) - the uncanny valley refers to the aesthetic regime in which human representations are too human, but not real enough. Although many roboticists steer clear of the uncanny valley in designing robots, it can be an interesting region of investigation in aesthetics and in cognitive science. Rather than calling it 'the uncanny valley', roboticist David Hanson and 
his team refer to this region as the "Path of Engagement", and they refer to the creation of androids (which are realistically human robots) as an extension of the art of figurative sculpture, which serves as a visual aid for human self-reflection (Hanson et al. 2005). "With intelligent and highly expressive depictions of humans, we gain a powerful mirror that can help address the question of "what is human"'(Hanson et al. 2005, pg 1728). The question of "what is human" is explored in both the sciences, through systematic observations, and the arts, through aesthetic experiences. In aesthetic experiences, the uncanny creates a sensation that can instigate reflection on human nature.

\section{Theoretical Framework}

\section{Theme Of Investigation: The Uncanny}

In 1906, psychiatrist Ernst Jentsch published "On the Psychology of the Uncanny" as a first attempt to characterize the feelings of the uncanny (Jentsch 1906). Jentsch steers clear of attempting to define the essence of the uncanny, since he observes that different things provoke uncanny feelings in different people, but the feelings themselves - of what the uncanny evokes- are universal. My exploration of the uncanny begins with Jentsch's observations. Jentsch characterizes the uncanny with what 
he terms as "psychic uncertainty" (Jentsch 1906): uncanny feelings arise when we are uncertain of something in our environment, while also being aware of our own limitations. The first example Jentsch offers is that of a fearful child, who does not understand the world while being at the same time acutely aware of his limitations in navigating the world. Another example Jentsch provides is the sensations of fear evoked by the night, or by a darkened environment, which arise out of not being able to clearly discern the features of the landscape, while also being aware that having the sense of sight limited may limit one's defenses or bring unpleasant surprises. Uncanny feelings occur when we don't know what to expect, or when something defies our expectations. Jentsch attributes the uncanny to a lack of intellectual mastery of our environment or over an object - it is the fear that accompanies the awareness of one's own ignorance. Automatons, for Jentsch, are the quintessential example of objects that provoke uncanny sensations, because they cause uncertainty about whether or not they are living. Eeriness can arise the moment we realize that we had been duped into believing, for a split second when we saw it out of the corner of our eye, that the automaton was a living being. Such an object thus challenges our intellectual mastery over it because it defies instant categorization. In a contemporary context, the uncanniness of an automaton doesn't necessarily come from the uncertainty over whether it 
is alive: the uncanny may also come from the uncertainty over its degree of intelligence, and from our not understanding how it achieves any degree of intelligence (Marynowsky 2011). Such uncertainty, however, may inspire wonder rather than dread. Uncanny feelings are not necessarily negative. The uncanny can function as a visceral reminder of the limits of our knowledge, inspiring us to seek more knowledge. It can serve as an interrupter of routine thought, opening up new spaces for playful exploration. The uncanny can challenge us to question our assumptions.

While there are many ways of evoking the uncanny, I focus on that which is felt when a humanoid object that upholds an illusion of sentience. The research-creation outcome of this project is a series of automaton-like figurative sculptures that generate uncanny but engaging experiences. Most of my sculptures are copies of myself in one way or another, and this was initially, on a conscious level, unintentional. It started from practical considerations; I am the cheapest and most accessible model to work with. But then I realized that the repetition of my face and body could be a means by which to visually explore the Freudian double. According to Freud, the double is uncanny because its naïve assurance of immortality brands it as a harbinger of death (Freud 1926). 


\section{Pragmatist Aesthetics}

I think that art is an effective communicator because it can directly transmit ideas and feelings that may not be accessible by analytical means, through a sensory and emotional experience. The uncanny is an exemplary idea and feeling that cannot be fully deciphered through analytical language. When an inanimate object conjures the illusion that it is a living entity, it can create an uncanny sensation that is universally acknowledged but uniquely experienced. As an artist, I create objects that produce uncanny sentiments of presence, in order to investigate what these are and how they function.

My work follows John Dewey's pragmatist view of aesthetics, as explained in Art as Experience (1934), in that I see art's function in society as the creation of experiences. Dewey argued that art and aesthetic experiences should be part of a healthy person's everyday life, rather than an occasional excursion to the museums (Dewey 1934).

Dewey saw the segregation of art from everyday life, not as a natural state of human nature, but as an unhappy outcome of the rise of nationalism, of imperialism and of capitalism. The task of the artist is then to restore the bridge between everyday life and the refined experiences that are works of art. Dewey therefore championed folk art and popular art, because these 
are fully experienced by the general public and they actively function in everyday life, as he believed all art should. My interest in bringing elements of puppetry into my practice is largely based on its status as an outsider art or a folk art. The Camp sensibility with which I approach my work is also a nod to the outsider and the popular art forms. "The connoisseur of Camp has found more ingenious pleasures," says Susan Sontag, "Not in Latin poetry and rare wines and velvet jackets, but in the coarsest, commonest pleasures, in the arts of the masses" (Sontag 1964, pg 8).

\section{Scope and Limitations}

While my body of work draws heavily on puppetry and robotics, it remains firmly sculptural. Since I create the work within the context of a visual arts school, I do not create theatrical scenarios for my puppet characters, nor do I create (or have the means to create) sophisticated robotics. I describe my works as puppets because of their potential to be moved and positioned in various ways; and while they have some autonomous motion, they are not automatons. The scope of this aesthetic study does not require full automation or even full mobility of the figures. My works have just enough motion to invoke some sensation of presence. In the art of puppetry, the best puppets have a well-chosen but narrow range of motion and gestures (Gross 2011). 


\section{PART 2: LITERATURE REVIEW}

\section{Brief Look at Contemporary Robotic Art}

The uncanny is often evoked in contemporary art through automation and interactivity, and here I look at some examples of such work. Greek artist Georgios Cherouvim created in 2014 the installation "the Debate", which features two male mannequins in suits standing at podiums simulating a political debate. Instead of heads, these mannequins have a geometrical form that lights up when they 'talk'. Their 'talk' does not consist of actual speech, but rather intelligible and irritating noises that evoke how the public perceives political debates (Cherouvim, 2014). The installation evokes the feeling of watching an actual political debate because the posture of the mannequins and the argumentative tone of the noises they

emit capture its key features. Australian artist Wade Marynowsky created robotic works that are hoop dress forms (the fashion is a reference the era of automatons) that have no actual head or face. In one installation, shown in 2014, "The Discreet Charm Of The Bourgeois Robot", the viewer engages in a conversation with the robot, which is teleoperated by the artist. Engaging in a conversation with the robot elicits the sensation that it is somehow sentient, despite its clearly non-human form. Artists have investigated the robot-puppet theme since the 1990s, with Ken Feingold's 
installation "where I can see my house from here so we are" in 1993 being one of the first. In this installation, the viewers themselves control the robots, and are able to communicate with other viewers through the robots. So, the robots act as intermediaries. The installation was set up in a hall of mirrors, which induced some confusion for the viewers, leading them to ask 'which one is me' as they controlled their robot and interacted with others. Feingold's robots in this installation had somewhat human hard mechanical faces that referenced ventriloquist dummies. Hyper realistic faces are not necessary to evoke a sense of presence. Canadian artist Morgan Rauscher's zeugen installation is a series of simple white mask-like human faces mounted on a wall, with eyes that follow the viewer around the gallery (Rauscher, 2013). The eyes are mechanical and respond to a motion detection system, so they evoke the feeling of being watched, even though there is no one watching, and even though the faces are blatantly artificial. On the other hand, if an object possesses a high degree of human likeness along with some motion, interactivity may not be necessary to give an object a sense of uncanny presence. Artist Nathaniel Mellor, for example, has an installation named "Singing Heads" in which three realistic android faces sing a song about freedom. The illusion of lifelikeness is broken by exposing the mechanism on the back side of the head, but the faces' texture and motion suggest lifelikeness. 


\section{The visual language of the human figure}

Although my works involve interactivity and some automation, I prefer to position my art closer to figurative sculpture because I work from the premise that imagery based on the human figure constitutes a universal visual vocabulary. Human expressions evoke empathy, perhaps more universally than other types of imagery: a smile, or a frown, is crossculturally recognized. I am particularly drawn to figurative works of art for this reason - for their widespread ability to communicate the human condition.

\section{Some Case Studies in Sculpture}

To support my claim that the figurative form is an effective communicator, I examine some case studies of artists that use the visual language of the figure, and the cultural function of their work.

\section{Hans Bellmer}

Hans Bellmer is best known for his grotesque yet beautiful doll constructions, which he photographed and published in Minotaure (the Surrealist publication) in the 1930s. Since my work consists in large part of doll-like figures, I consider Bellmer part of my artistic lineage. Although I find the misogynist aspects of his work problematic, it is relevant to consider his use of the human form to make statements of 
political resistance in his historical context of Nazi Germany (Krauss 1981 1985; Lichtenstein 2001).

When the Nazi party took power in 1933, Bellmer made a pronouncement to give up all work that could contribute to the government, and set out to produce work that would constitute a critical response. Regarding the grotesqueness of his dolls, Bellmer said that if his work seemed scandalous, it was because he believed the world was scandalous (Lichtenstein 2001).

Contemporary readings of Bellmer's Dolls argue that the dolls are an expression against the rise of the Nazi party, and a form of passive resistance (Krauss 1981, 1985; Lichtenstein 2001). The deformed grotesque but oddly beautiful dolls are an unabashedly provocative rejection of the Aryan ideal of the body.

In Nazi Germany, hatred of the degenerate was fomented, at the heart of which there was a genuine fear of the threat 'the degenerate' posed to its society. Representations of what was deemed degenerate were systematically labeled and censored. The danger of the degenerate is that subjects could start to identify with 'the degenerate' to contest the political 
status quo. Butler pinpoints such identification as the groundwork for political mobilization (Butler 2006). Hans Bellmer's dolls are categorically 'degenerate bodies', ones with which he identified, ones which resonated with Breton and the surrealists in Paris who published his photographs in Minotaure in 1934.

Bellmer's dolls are often posed in what seem like hysterical contortions, and this is not coincidental. The $19^{\text {th }}$ century psychiatrist Cesare Lombroso linked hysteria directly with degeneracy. Hysterical women were seen as a dangerous and powerful negative force on society. The image of the hysterical woman was appropriated and repeated by surrealist artists, such as Man Ray, and André Kertész. They repeated the construct of hysterical woman as a danger to society, but they also identified with it. They wanted to identify themselves as dangers to a society that upheld values against their own principles. Poet and surrealist leader Andre Bretton described hysteria as "the greatest poetic discovery of the end of the nineteenth century" (Lichtenstein 2001). By exposing the instability of normative beauty, a symbol of abjection becomes a symbol of political agency (Butler 2006). The fascination that surrealist artists and non-conformists held with hysteria was fixed through the process of reiterating and identifying with the construct of Hysteria, which came to 
include and be embraced by men. So, aesthetic representations of hysteria, such as Bellmer's dolls, functioned to transform and pry open the restriction around gender identities (Lichtenstein 2001).

Some feminist scholars go as far as vindicating Bellmer with the argument that his dolls comment on the construction of gender (Krauss 1981, 1985). However, there is no evidence in any other part of his life or art that he had any consciousness of feminist ideas. Critic Sue Taylor asserts that male sexual curiosity and domination are the theme of his work and that the sexualized young female body was Bellmer's sole artistic subject (Taylor 1996). In his 1934 essay "Memories of the Doll Theme", he imagined little girls at play and the "casual quiver of their pink pleats", and he despaired "that this pink region" was forever beyond him. In closing his essay, Bellmer envisions the manufacture of the doll in their image, which he can probe "with aggressive fingers" (Taylor 1996). Aside from this blatant pedophilia, there are clear intimations of rape in some of his photographs, as noted by his biographer Peter Webb (Taylor 1996; Foster 1991). In writing about his second doll, Bellmer openly expresses his drive to "master his victims", revealing a patriarchal fantasy of control. This is fundamentally incompatible with any form of feminism. So, while he is using the body to speak against fascism and to challenge normative 
structures that include sexuality, he is not approaching this from any feminist perspective.

What is most interesting to me about Bellmer's work is the vocabulary he developed that was based on the human body. He describes the photographs of the second doll as "a series of endless anagrams" (Foster 1991). The metaphor of the anagram was central to his conception of the dolls, suggesting that the rearranged body parts reveal multiple meanings of the female body (Lichtenstein 2001).

Bellmer specifically chose to speak with bodies of adolescent girls, and while there is an uncomfortably pedophiliac tone in the development of this language, it should be noted that, as pointed out by Julia Kristeva, the inbetween-ness of the adolescent body works as a signifier of potentiality and rebellion(Grant 2010). This inbetween state interrogates sexuality and is resistant to normative structures (Grant 2010). It is a site on which seeming contradictions are reconciled: the abject and the beautiful; the grotesque and the sexy.

The photographs of Bellmer's dolls iterate and reiterate tropes of sexuality (the girlish shoes, the seductive poses, the clothing that only partially 
conceals the bodies). Repetitive tropes are inherently unstable (Butler 2006), and Bellmer pushes this instability by reworking abjection into objects of beauty and desire. The sexualization of the abject dolls challenges the norms of respectability that repress sexuality, and it functions as a method by which to invoke beauty. Beauty is also invoked by the sensitivity to aesthetics demonstrated in the photographs. Bellmer states defiance by creating and reiterating forms that are both abject and beautiful. In the repetition of this grotesque beauty contradiction, he creates a space for the non-conformist in the fascist world in which he lives.

While Bellmer's dolls do not inspire my work directly, his work serves as a worthwhile example of how the human figure, specifically the uncanny figure, can function as a language to express socio-political ideas. Although I'm interested in this subversive aspect of Bellmer's dolls, I position my own work in opposition to Bellmer's work in other respects. While Bellmer objectifies the bodies of girls with his dolls, I'm seeking to work in the opposite direction: to render objects into subjects imbued with life-like qualities. 


\section{Duane Hanson}

Duane Hanson is known for his life-sized hyper realistic sculptures of everyday people - his works are so realistic that they are often mistaken for actual people. His use of everyday clothing and props, which evoke a sense of relatability and disturb the boundaries between art and life, has been a direct influence on my work.

Hanson's sculptures are so realistic that they are often overlooked, in part because of their technical achievement, but also because of the familiarity of the scenes he depicts: iconic American characters, the 'regular people' of the middle and lower classes. His work examines the failure of the American dream with both social criticism and human compassion. The imagery of his sculptures stand in stark opposition to the idealized American imagery fixated on youth, thinness, and wealth. He expresses the fatigue and the frustration of his subjects with some tenderness. In 1978, Hanson stated "People, workers, the elderly, all these people I see with sympathy and affection. These are the people who have fought the battle of life and who now and then show the hard work and frustration" (Doss 2006, pg 12). 
Hanson's works were comprehensible across class and culture. He clearly expressed his sympathy and affection through his sculptures. No prior art knowledge is required to fully experience Hanson's work. It is made accessible by the recognizability of the characters: the viewer can read their troubled faces and relate to the pathos of their existence.

However, Hanson did not enjoy many accolades from contemporary American critics, and was much better received in Europe than in America throughout his career. In a New York Times review in 1972, his work was declared "an imitation of something that is not art", and in the Saturday Review the same year Rosalind Constable stated that it is "difficult (if not impossible) to see what makes them art" (Bush, page 47). In 1984, contemporary art historian Carol Donnel-Kotrozo wrote that Hanson's characters were but "deadpan clones, objects with no discernable message" (Donnel-Kotrozo, pg 280-281).

Although Hanson's figures do look like copies from real life, his process reveals that his characters are far from simple copies of individual models. While he does use casting as part of his process, the completed figures rarely resemble the original model, and are often a composite of several models (Bush, page 49). Each character is painstakingly created with 
months of planning, which entails interviewing potential models and shopping for clothing and props. They are not copies, but rather invented portraits configured with carefully chosen props and gestures.

Art historian Kirk Varnedoe documents Hanson's process, revealing that his "reality is a constructed synthesis in which no part is left to chance"(Varnedoe, pg 20). According to Varnedoe, "the relationship between his imagined typologies and his experience of individuals is neither simplistic nor consistent." (Vanedoe, pg 21). Hanson has many interviews and "auditions" with individuals to pose for a given "role". $\mathrm{He}$ spends time getting to know his models, and their personal and physical characters are integral to the final realization of his idea. The clothing and props are inextricably and significantly integrated into each piece, psychologically as well as physically. Hanson considers personality: how would this person hold such a thing, but he also considers aesthetics: the proportions of objects to the body, the formal composition of the body's posture, and the overall color balance of the piece. Even though each scene is carefully arranged in position and color with aesthetic design considerations, Hanson maintains that "intuition plays a key role" in his process (Bush, page 87). “The effort must not look noticeable;" he says, "everything must give an impression of naturalness." (Bush, page 87) 
Perhaps everything was too natural for contemporary critics, but despite their dismissals, Hanson's work remains absolutely impossible to ignore. Donnel-Kotroso, while dismissing Hanson's work as “deadpan cloning” (page 280), acknowledges that his "desire to order and to control the world by paralleling its structure, by capturing its objects in material form... is also desire for meaning and value.” (page 282)

This unabashed desire for meaning and value is something I share with Duane Hanson, along with his passion for the human form as a subject matter and his desire to create art that is accessible to non-connoisseurs. In 1981, Hanson wrote "What can generate more interest, fascination, beauty, ugliness, joy, shock, or contempt than a human being?” (Doss, page 11).

In my own work, I have experimented with situating the figure within a context with real clothing and props from everyday life. While Hanson is influential in my work, the idea of using clothing and wigs on figures first came to me from the tradition of dressed statues in Latin America (See for example, Mo 1992). My interest in figurative sculpture began with an 
interest in the imagery of Latin American catholic mythology, a fragment of a cultural root structure I'm always seeking.

\section{Ana Maria Pacheco}

I'm drawn to Ana Maria Pacheco in part because of her cultural background, having fled from a South American dictatorship in the 1970 . My mom is from Argentina, and my dad is from Chile. They were each forced to leave their respective countries under political persecution, in the 1970s. They each fled and went into hiding in Peru, which is where they met. I grew up in isolation in Canada as an only child without any surrounding relatives or community; although my parents shared a common trauma, they were each from different countries. I grew up with the culture passed on from my parents, but couldn't find where to contextualize it. Flights to South America were beyond our means as I was growing up so I never got to know my extended family. My origins feel like a mysterious parable and I'm always seeking clues and traces of what happened, of where I came from. I seek it in magic realist novels, in Latin American history books, and in art, from kitsch images of saints to contemporary greats such as Ana Maria Pacheco. 
Ana Maria Pacheco was born in 1943 in Brazil, and did all her formal education in Brazil. In 1973, she moved to England on a British Council Scholarship at the Slade School of Fine Art. Although she was not in direct danger, there was political repression at the time of her escape, and that historical legacy resonates throughout her work. She is a painter and printmaker as well as a sculptor, but I will focus on her sculptural work. She makes life-sized wooden carved figures that are set up in theatrical scenes throughout which the viewer can walk. The carved figures are realistic, but not hyper-realistic; some natural wood features are allowed to show through, and they make no pretense of imitating human anatomy, but they are nonetheless hauntingly real with their emotional resonance. Critic Shelagh Hourahan, in experiencing Pacheco's life-sized characters, “...grew to love them, to feel their humanity and to wonder at their strength and vulnerability" (Hourahan, page 19)

Pacheco's work is linked to magic realism for her open-ended style of storytelling; her installations read like mysterious parables. In her own words:

"Lately I have been more interested in groups rather than in single figures. One of the biggest problems I have found in using groups of figures is that as soon as one puts them together, spectators immediately begin to build 
up a story; this is almost impossible to avoid. What I am trying to do is not so much to illustrate events but find a way of working in which I can explore rather than confirm the expectations that onlookers bring with them." (Szirtes, page 26).

Pacheco's works are provocative but ambivalent. She creates an elaborate scenario and leaves the audience to figure out what is going on. So, her ambiguity is more pointed than Hanson's. Pacheco's ambiguity is created through the palpable yet conflicting emotions of her characters, in contrast to the ambiguity created through the dispassionate expressions of Hanson's characters. Pacheco's work is also loaded with several layers of cultural meanings with its multifaceted references to history, mythology, and literature.

The work "Dark Night of the Soul”, for example, references a poem and treatise by St. John of the Cross, though the work itself superimposes other historical and religious references. There is a clear reference to St. Sebastian, but the image of the bound and hooded figure is also unmistakable for anyone familiar with the political events of South America in the 1970s, especially considering the artist's origins. 
Critic Tamara Stuby notes two significant ways in which Pacheco's work departs from representational traditions in sculpture. For one, it insists that the audience cohabit the same space as the characters in the drama, which is a presentation strategy in direct opposition to that used historically in sacred or sculptural space. Secondly, the spectators find themselves in an active role once they are within the work and surrounded by her figures (Stuby page 114). By inviting the viewer to move within the installation, the protective illusion of invisibility is removed, which plays on the notion of 'witness'.

Pacheco's use of space is of particular interest to me, as I also like to create work that cohabits the same space as that of the audience. Her characters, despite being far from realistic, come to life through their scale and through the power of their emotional expression.

\section{Blurring the Boundaries between Art and Life}

Both Ana Maria Pacheco and Duane Hanson create work that blurs the boundaries between the artwork and the viewer. This is achieved by the human-sized scale of the works as well as their placement within the space of the viewer. Their figures evoke an uncanny sense of presence: Hanson through sheer realism, and Pacheco through formidable emotional expressions. 
Another way in which figurative sculptures blur the boundary between art and life is when they are used as stand-ins for actual people. Photographer Suzanne Heintz (Heintz 2014) playfully constructs stereotypical and clichéd family scenarios with a mannequin husband and child as standins. In this example, the realization that the husband and child are dummies produces an almost involuntary chuckle, as Heintz uses the discomfort of the uncanny to create humor. Another, very different, example of figurative sculptures as stand-ins can be found in the remote and nearly abandoned village of Nagoro in Japan, where artist Ayano Tsukimi has replaced the departed residents with dolls in their likeness (Schumann 2014). She started making the dolls when she returned to her hometown after over a decade's absence to find that the town's population had dwindled to 35 , so she started repopulating the town with dolls. The dolls are meticulously placed into the scenes of everyday activities: working in the fields, waiting for the bus, teachers and students populate the classroom. "I don't like making weird dolls, but people who blend into the scenery," she says (Schumann 2014).

\section{The Uncanny in figurative sculpture}

Uncanny sensations often surface when a lifeless object sits in place of a living person; the realization that one has mistaken the object for an 
animate being arouses a momentary terror, often followed by a lingering feeling of creepiness. This uncertainty between living and inanimate is, for Jentsch, the most quintessential example of the uncanny (Jentsch 1906). Freud, on the other hand, emphatically disagrees (Freud 1919); he does not believe that the uncertainty between living and lifeless is the root cause of the uncanny sensation. His analysis of Offenbach's Tales of Hoffman points out that the feeling of dread in this story comes not from Nathaniel's love for the automaton Olympia, but from his fear of 'the Sand-Man, Coppola (later Coppelius), which for Freud, somehow comes down to a repressed fear of castration. Freud points out that children do not sharply distinguish between living and lifeless objects, thus they are at peace with this uncertainty, and that they have no fear at all of their toys coming to life, and may even wish for it (Freud 1919, page 9). Freud instead concludes that, in general terms, the uncanny is a hidden yet familiar thing that has undergone repression, which then emerges into the open. Artwork that triggers an uncanny sensation does so by unearthing common yet repressed fears and insecurities. Hans Bellmer's dolls exposed the fascist fear of the degenerate body (Krauss 1981, 1985; Lichtenstein 2001). Ana Maria Pacheco's figures reveal raw powerful emotions that may be difficult to confront. Suzanne Heinz challenges the depth and authenticity of the institution of marriage and the nuclear 
family. Automatons and lifelike figures bring to light our common fear of death, because we instinctively associate lifeless bodies with corpses (Mori 1970). Duane Hanson's hyper-realistic figures are so precise in their details that they could pass for embalmed corpses. Tsukimi's dolls directly reference death in their likeness of people who have died and people who have otherwise left. Aside from unearthing our common fear of death, automatons and lifelike figures may expose other fears, fear of an object coming to life, or any number of personal fears. The uncanny may cause discomfort; but it can create an experience in which we are forced to face our fears, our insecurities, and our assumptions.

\section{Pushing the envelope of lifelikeness: Humanoid Robots}

\section{and Androids}

As Freud suggested, it is entirely possible for objects to evoke a sense that they are alive without triggering the uncanny, and indeed, humans have a tendency to personify and anthropomorphize their possessions and tools. In 2005, Rosalind Picard, founder of the affective computing group at MIT, and psychologist Timothy W. Bickmore published an in-depth investigation of long-term computer-human relationships, which noted that people typically (and unconsciously) respond socially to computers 
(or other tools) when provided with appropriate social cues (Picard and Bickmore 2005). They designed a computer program with relational features intended to establish and maintain long-term social-emotional relationships with their users and test it in a controlled experiment. They found that the task outcomes were greatly improved in the group that had an emotional connection with the computer than those without, and that users who had a social-emotional relationship with the computer found the tasks more pleasurable. It is perhaps this desire for a happier and more productive world that drives researchers towards creating social robots, with which we can establish an emotional bond.

Social robots are machines whose purpose is to interact with humans in a wide range of applications, whose functions range from entertainment to therapeutic. The therapeutic possibilities for social robots have been particularly promising. PARO (PARO Robots, 2014), for example, which looks like an adorable cuddly seal-like creature, has been shown to have very positive effects on elderly patients with dementia (Wada et al. 2005; Kidd et al. 2006). It interacts with the patients in a similar way as a small animal would: it purrs and coos, it can detect touch, sound, light, heat, and movement, and it can recognize its own name: PARO is like a pet, providing all the psychological benefits of caring for a pet, but it is 
designed for the cognitively impaired, who may lack the basic ability to care for a live animal. PARO was thus, like animal-therapy, shown to reduce anxiety in elderly patients with dementia, and was also shown to help increase social interactions between patients (Kidd et al. 2006). Another care-giving robot for the elderly is the GiRAF+ (Giraff Plus 2014), a robot that provides some social companionship, but also the necessary monitoring for the elderly to be able to live independently. The robot can monitor for blood pressure and watch for accidents; it also has the ability to facilitate virtual visits from relatives or caregivers through a skype-like interface (Coradeschi et al. 2014). On the other end of the age spectrum, the social robot Kaspar (University of Hertfordshire 2015) has been designed to help children with autism learn to better read and express emotions, by providing the child with a training ground for social interaction that is simpler, predictable, and non-judgemental. Studies using Kaspar with autistic children has provided some evidence that practicing social interaction with Kaspar helps them better interact in social settings (Robins et al. 2008; Robins et al. 2013). While many of the functions for social robots are therapeutic, there is also an interest in developing social robots as home companions to help with household chores. One of the first such home robots was ARMAR (Karlsruhe Institute of Technology 2015), which can do kitchen tasks such as loading 
and emptying a dishwasher, and another is Maggie (Robotics Lab Universidad Carlos II Madrid 2015), which is one of the first robots to demonstrate some ability for autonomy (Castro-González 2014). Perhaps the strongest contender to become the world's first family robot is Jibo (Jibo 2015) designed by Dr. Cynthia Breazeal's group at MIT, which is already selling pre-orders at $\$ 499$. There are many more examples of social robots, but one key feature all this research shares is the desire to have machines communicate and connect with humans on some emotional level.

Knowledge from the arts of puppetry and animation has been used to design social robots that emote recognizable expressions with which to establish human connection. Ribiero et al for example, explicitly refer to Disney's animation principles and Henson's puppetry techniques when describing the design of their humanoid social robot EMYS (Ribiero et al. 2012). Their design was tested with a quantitative study measuring how accurately people were able discern EMYS's emotions. Out of the six basic emotions the robot emoted (anger, disgust, fear, joy, sadness, and surprise), the only one not recognized by a majority of participants in the study was disgust, which proved to be too subtle for this particular robot's basic facial features. 
Design in social robotics has also relied heavily on the cognitive science of emotional expression. In 1969, Ekman et al revealed that there are six basic emotional expressions that are universally and cross-culturally understood: anger, fear, joy, sadness, and surprise (Ekman et al. 1969). Ekman later added contempt to the list of universally recognized expressions (Ekman and Friesen 1986). In 1988, Ortony, Clore, and Collins proposed what is now known as the OCC model, which specifies up to 22 emotion categories and breaks down the processes that lead to these emotional states as valence (positive or negative) reactions to events, agents, or objects (Ortony et al. 1988). This model, along with some modifications of its logical structure (see for example Steunebrink et al), has been the basis on which scientists have been able to design emotionally expressive robots. For better functioning social robots, it is absolutely necessary to imbue them with functional emotions, not only to better interact with humans, but also to better navigate complex unpredictable environments. Evolutionary scientists believe that animal and human emotions evolved as adaptive mechanisms to help them function optimally (see for example Gould 1982 or Damasio 1994). It follows that emotional mechanisms could lead to more adaptive and intelligent machines. 
Cynthia Breazeal's group at MIT has done pioneering work in advocating for emotional robots and in creating social robots that express emotion (Breazeal 2003; Breazeal and Brooks 2005). One outcome of her research is a concrete method by which to quantify the expression of emotions, which she documents in the implementation in the 'Kismet' robot (Breazeal and Brooks 2005). Affective states are quantified along three dimensions: arousal (excited/tired), valence (positive/negative), and stance (interested/frightened). Positive valence means that its lips turn upward, the mouth opens, and the eyebrows relax; on the other hand, as valence becomes negative, the brows furrow, the jaw closes and the lips turn downward. When Kismet becomes aroused, the ears perk, the eyes widen, and the mouth opens. Stance determines the direction in which the robot leans: it leans towards the stimulus when interested and away from the stimulus in when withdrawing (Breazeal and Brooks 2005). An individual's affective state, however, is not singularly reliant on external stimulus: internal factors such as motivations and past experiences also contribute to affect. Furthermore, an individual's emotional expression is mediated by cognitive and behavioral functions. The breakthrough result in Breazeal's research is that Kismet's emotional expressions are accordingly constructed from the contributions of many processes. 


\section{The Uncanny Valley}

All the robots discussed thus far are unmistakably non-human, thus steering clear of the uncanny valley, an idea originally proposed by Japanese roboticist Masahiro Mori in 1970. Mori proposed a relationship between an entity's human likeness and the perceiver's affinity for it, shown in figure 2 (Mori 1970). Mori's prediction is that as the entity becomes more human-like, the perceiver's affinity for it increases until it gets to a point where it is too humanlike and somehow not human enough, so as to cause revulsion. But, as the entity becomes more human, the perceiver's affinity towards it once again increases, with a maximum affinity towards a healthy person. Mori labeled the region of discomfort in the graph as 'the uncanny valley', likening it to the feeling one gets from being confronted with a corpse. He based this prediction on observations of how people react to a handshake with a highly realistic prosthetic hand. He noted that motion changed the amplitude of the curve; a puppet is more relatable than a stuffed animal, but also a zombie is much more terrifying than a still corpse. Mori's original paper was not based on any quantitative measurements, but was rather a description of his observations and predictions. However, these graphs have been useful in illustrating the phenomenon of heightened sensitivity towards human-like entities. It is a common observation that the more anthropomorphic the 
depiction of a face becomes, the more demanding we become in our expectations for realism to aesthetically please us. For example, moving one facial feature by $1 \mathrm{~mm}$ changes a face from being considered attractive to unattractive (Etcoff 2000).

To differentiate types of robots as well as intents in design, roboticists use the terms 'humanoid robot' and 'androids'. The term 'humanoid robot' is used to describe social robots that have human characteristics but are clearly non-human and thus fall on the left side of uncanny valley, and most designers of commercially viable social robots stay within this regime. The term 'android' refers specifically to a humanoid robot that exhibits highly realistic human features, and those who design androids do so with the specific intention of exploring the uncanny valley.

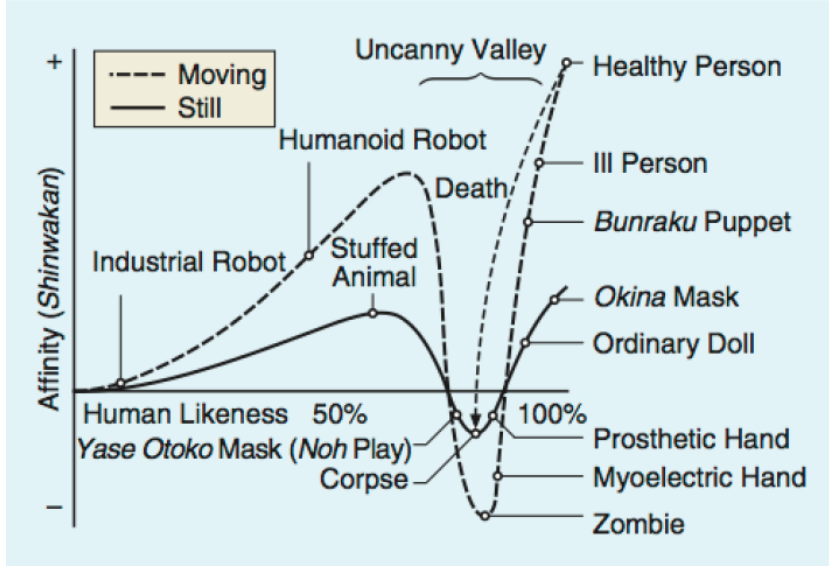

Figure 1: The Uncanny Valley (Mori 1970) 
In 2006, computer scientist Karl MacDorman published a study in which he used answers to survey questions to quantitatively recreate the uncanny valley (MacDorman 2006). In the first part of the study, he showed participants a series of photographs that slowly morphed from a clearly artificial humanoid robot to an android to a healthy human. The photographs were labeled from 1 (most mechanical) to 9 (most human like) to form the horizontal axis of the graph. Each participant was asked to rate each photograph according to how eerie it seemed. The results showed a peak in eeriness at the midpoint between the most mechanical entity and the most human one, as expected from the uncanny valley. In a second study, he asked participants to rate video clips of humanoid and android robots that varied from mechanical to humanlike, but these results were not so clear-cut: there was no discernable shape to the graphs produced. The author concludes that when motion, behavior, and context come into play, there are many more factors, apart from human likeness, that contribute to feeling the uncanny. The morphs of still images reproduce Mori's prediction because there was only one variable (human likeness) being probed. Given all the other factors that contribute to (or take away from) the uncanny, MacDorman concludes that it should be 
possible to design androids that avoid the uncanny valley by varying factors other than human likeness.

Indeed, in the same year, robotics designer David Hanson published a paper suggesting that he was able to eliminate the uncanny valley with aesthetic tuning (Hanson 2006). He draws from evolutionary and psychological studies to postulate that it is illness, rather than death, that causes the uncanny sensation, and that avoiding specific perceptual triggers may be the way to avoid the uncanny valley regardless of the level of realism. He performed an experiment similar to MacDorman's experiment described above, where he showed participants a series of photographs that morph from mechanical to human. In the control group, he used MacDorman's series of photos and reproduced his results; in the study group, he aesthetically tuned each of these photographs and found that the uncanny valley disappeared. He concludes that good or bad design is more important to how the perceiver reacts to an entity than its level of humanness.

Since androids are meant to deliver an experience that is not solely visual, but also interactive, factors beyond visual design must be considered when studying how people perceive them. The behavior of the android, for 
example, was found to be a crucial factor in mitigating the uncanny valley. In a 2010 study by Becker-Asano et al. the researchers studied interactions between humans and an android that was tele-operated by a live person (Becker-Asano et al. 2010). They found that only $37.5 \%$ of the interviewed participants reported an uncanny feeling, and that 29\% reported enjoying the conversation. They also found that uncanny feelings were minimized when the robot/puppet took on the role of entertainer.

The degree to which people feel comfortable around androids also depends on an individual's personality and experiences, but most importantly, people's comfort levels with androids increase with more exposure to them. In 2013, Haring et al published a quantitative study in which participants interacted with and played a 'trust game' with an android robot (Haring et al. 2013). The participants were surveyed about how they perceived the robot before and after the interactions and game. Specifically, they were asked how animate, how likeable, how intelligent, and how trustworthy the robot seemed. The answers to these questions varied depending on the participants' personalities (a personality test was also administered, and extroverts tended to feel more trust towards the robot); answers also varied depending on whether the participants had non-human emotional connections (people with pets and those involved in 
gaming activities also tended to feel more trust toward the robot). Most interestingly, the answers to the questions changed after the participants interacted with the robots. After interacting with the robots, people found them less lifelike, less intelligent, but more likeable and trustworthier. The correlation between 'less intelligent' and 'more likable' is consistent with Jentsch's observation that an object's uncanny qualities disappear as soon as we gain intellectual mastery over it.

\section{The Case in Favor of the Uncanny}

While many designers try to avoid the uncanny valley as they aim to build humanoid robots that better interact with humans, it is worth noting that the uncanny can be advantageous to better understanding our preconceptions. Uncanny sensations arise when a human-like entity fails to live up to expectations, so androids may be useful tools to probe what, exactly, are our expectations of humanity. Roboticists Karl MacDorman and Hiroshi Ishiguro argue that very human-looking androids are an ideal tool for cognitive and behavioral research as they can be controlled much more precisely than human actors (MacDorman and Ishiguro, 2006). Understanding how people react to almost-human entities can help us better understand our subconsciously embedded conceptions of humanness. 
Hiroshi Ishiguro's lab has been a world leader in creating very human-like androids (Fitzpatrick 2014); much of Ishiguro's motivation lies in better understanding the human condition, and is driven by an investigation of what constitutes a human presence. He states his research goals as twofold: "to realize an advanced robot close to humankind, and at the same time, the quest for the basis of human nature" (). The latter goal, being open-ended and multi-faceted, is perhaps more of an artistic (or philosophical) goal than a scientific one.

Although the motivation to make social affective robots is for the most part practical, as humans function better when they are emotionally connected to their tasks and tools, the motivation to build androids is perhaps more poetic. Unlike Jibo, which is already being sold online, androids are not presently being put to everyday household use. The most exciting use for androids is currently for studies in cognitive psychology, which suggests that we create androids, not to serve us but to better understand ourselves (Ishiguro 2006; MacDorman and Ishiguro 2006). Android science is an extension of figurative sculpture, whose function is to instigate reflection on the human condition. Indeed, roboticist David Hanson published a paper in 2005 that explicitly connected his work in developing hyperrealistic androids to the tradition of figurative sculpture dating back to the 
Greeks (Hanson 2005). Philosophically, androids help us reflect on what it means for us to be human, and the uncanny may serve as an instigator for such reflection.

\section{Why, exactly, are androids uncanny?}

Jentsch associates the uncanny with the cognitive dissonance of confronting new knowledge (Jentsch 1906). He uses the example of a sunset: to someone who does not understand that the earth rotates around the sun, the idea that the sunset has nothing to do with the movement of the sun but with the earth's rotation around it can seem very disorienting and uncanny. Similarly, perhaps seeing a machine that resembles a human causes discomfort because it forces us to confront the idea that we too are machines of sorts.

Philosopher Stanley Cavell disagrees with Freud's denial that the automaton is the source of uncanny sensations (Cavell 2006, page 86-89). He notes although "there are no marks or features or criteria or rhetoric by means of which to tell the differences" between a living being and an inanimate object (Cavell 2006, pg 89), it is a difference human beings strongly and instinctually recognize. Hence, our inability to rationally articulate this difference (between living and inanimate), while also being 
emotionally certain of it, creates the cognitive dissonance that evokes the uncanny.

René Descartes philosophically separated humans from the universe, which he believed to be perfectly mechanical and deterministic, with the specious argument of mind-body duality. Descartes imagined a mechanistic clockwork universe, whose automata extended to animals, but not to humans by virtue of the intangible concept of the 'spirit' or 'soul'. The soul, for Descartes, was believed to be the source of human emotion, thought, and personality, in sum, the source of our consciousness, what makes us more than mere machine governed by the laws of nature. However, contemporary belief is that emotions and consciousness appear to have evolved from evolutionary pressures (Gould 1982), and that emotion and many features of consciousness can be explained by neurophysiological functions (Damasio 1994). The more we learn about ourselves, the more we realize that there are mechanisms that can explain even our most intimate emotions, that we are but one big complex biological machine. Recent studies have suggested that our impulses are determined by our brain chemistry (Arkowitz and Lilienfeld 2014), or even by brain parasites (McAuliffe 2012). Such contemporary knowledge clearly problematizes the existence of the soul; at the same time, I think 
that facing the prospect that our nature is purely mechanistic can trigger the uncanny. What makes automatons and lifelike figures uncanny is the illusion of a soul precisely where there should not be one, leading to those uncomfortable questions about our own machine-like nature.

There is strong speculation that the first spark of life on earth was an inevitable chemical reaction (Wolchover 2014), implying that there isn't a clear binary between life processes and chemical processes. All living species, including us, are probably part of a larger universal mechanism, governed by physical laws, perhaps merely cogs in the clockwork universe that Descartes imagined. Emotions are not unique to our species, and they could very well be the result of adaptive evolutionary mechanisms, but that doesn't make them any less valuable, magical, and marvelous. It is perhaps not necessary to separate ourselves from the rest of the universe to value them.

But, we face the uncanny whenever we face the intrinsic connection between all matter in the universe. A carbon atom, which was fused in the sun, may have started its life on earth in the soil, grown into a tree, cut down and built into a house that, after a long happy run, eventually decomposed back into the soil and grew into a plant you ate, to become 
part of you. We are made up of carbon, oxygen, hydrogen, and other atoms. The desk on which I write contains carbon atoms. It is possible that the carbon atoms in the desk and the carbon atoms in my body came from the same star, because we are all made out of stardust, albeit very carefully arranged, biologically mechanized stardust. This is poetic, but also somewhat terrifying, because it implies that we are, after all, a mechanistic arrangement of things, and uncanny feelings occur when we confront and question the subject-object binary.

\section{Puppetry: The Art of the Uncanny}

Puppets have the unique quality of existing within the space between subject and object. The classic tale of Pinocchio is about an object over which control is lost. It illustrates the underlying tension between the puppet and puppeteer as they vie for control over the puppet, a tension that erodes the line between subject and object. Critic and theorist Tzachi Zamir argues that our division of subject and object is one that is not intrinsic, but learned in childhood, and that puppetry invites the viewer to revisit a different relationship with objects (Zamir 2010). In this sense, puppet theatre undermines our attachment to subjectivity: it foments an empathic relationship to an object. 
Empathy towards objects can be a tricky area to navigate, as it is not necessarily a desirable state for everyday life, though it is a theme that has existed in mythology. In the ancient myth of Pygmalion, Pygamalion falls hopelessly in love with an ivory statue he creates and names Galatea. Critic Tzachi Zamir argues that Pygmalion's love for Galatea did not stem from a wish to see her transformed into subject, but that he loved her as object (Zamir 2010). Pygmalion stops himself from revealing his true wish to the gods, and asks them instead for someone like her as a bride. Zamir argues that his true wish was not that she be transformed into a human (as happens in the end), but for the gods to condone and validate his love for the object, which he couldn't bring himself to say. There is a universal taboo against having certain emotional attachments to objects, but puppetry allows us to break that taboo in the limited and playful framework of an imagined world whose residents are non-human, and our empathy for them occurs within their worlds in the context of a cathartic theatrical experience. Puppets, for the most part, unlike androids make no attempt to realistically imitate humans - at best they are grotesque caricatures.

In the theatricality of puppetry, puppets fulfill an entirely different role than human actors. A puppet, as it belongs to the realm of objects, can 
only partially manifest any character it plays; perhaps it is more apt to say they play caricatures rather than characters. However, Tzachi Zamir argues that this partial manifestation of personhood is what allows puppets to touch on facets of human experience that human actors, trapped as subjects, cannot reach.

In Heinrich Von Kleist's unique essay "On the Marionette Theatre”, the author compares human dancers to marionette dancers, staging discussion about the marionette's "inhuman grace of motion" (Von Kleist 1810) with a ballet master. They conclude that the magic in the puppet's motion comes from its very limitations: its inability to individually control its limbs, and its poetic dependence on the physics of the system that holds it and moves it. The manipulator must be the one to learn to yield to its weight and momentum, in order to best interpret the marionette's unique range of motion. So the marionette performance is something of a duo, but the manipulator becomes invisible to the audience, transferring her presence to the puppet. But even as the puppet expresses a perfectly human gesture, with touching humanity, there is always something in its motion that reminds us that it is an object. Critic, and puppetry expert, Kenneth Gross notes that the relation between the puppet and the audience at the height of a performance is akin to the relation of a mad 
person with an object: empathic but uncertain. And so, he links puppetry with explorations of madness (Gross 2011).

One element of madness is a persistent state of psychic uncertainty, and Jentsch (1906) notes that one that is succumbed to madness feels a heightened sense of the uncanny in his or her everyday surroundings. For Freud, however, the uncanny is not about psychic uncertainty but is the feeling that occurs when something that is repressed, that ought to be hidden, is placed out in the open. So, a full descent into madness is not necessary to experience uncanniness with the ordinary, since the uncanny exists in our dreams and our unconscious. Kenneth Gross points out that puppet theatre functions by connecting to our dreams and fantasy rather than by trying to emulate any realistic human drama; he calls puppetry the "poetry of the unconscious" (Gross 2011).

I think that explorations of the unconscious imply a willful madness of sorts: madness as an expression of rebellion - a refusal to be well adjusted to a world that contradicts one's values. Expressions of the intuitive, as well concerns with fantasy and with madness can be found in Dada, which to a large extent was an expression of rebellion against a society that led them to the devastation of world war one. Indeed marionettes had a place 
in the movement since its inception at Cabaret Voltaire in 1916. Leading members of the movement, Sophie Taeuber and Hannah Hoch each produced marionettes among their many works.

The Dadaists were probably not the first, and certainly not the only ones to embrace puppetry as a playful yet politically subversive gesture. Kenneth Gross's exploration of puppetry 'Puppet: An Uncanny Life” repeatedly stumbles into the theme of rebellion, and finds the puppet "refusing the control of narrow social rules and established forms of politeness" (Gross 2011, 141). But, as Gross continues, it becomes evident that such rebellion comes out of innocence, Gross continues “The puppet's speech is often close the unformed babble of infants, the naked gestures of small children." (Gross 2011, 141) Puppets are like the child that exposes the naked emperor; they are impulsively sincere. Puppet artist Peter Schumann references this earnest tradition of puppetry in Bread and Puppet's mission statement: "we hope that our plays are true and are saying what has to be said, and that they add to your enjoyment and enlightenment"(from Bread and Puppet's website: 
Peter Schumann founded Bread and Puppet Theatre in New York City in 1963, with its headquarters based on the lower east side of Manhattan. In its first few years, the theatre primarily functioned within the resistance movement against the Vietnam War, and in doing so, created the images of giant puppets and effigies that became iconic of the opposition to the Vietnam War. In 1974, Bread and Puppet moved its base to a large farmhouse in Glover, Vermont, where they hosted the annual 'Domestic Resurrection Circus', a large puppetry festival and pageant, until 1998 when they became too large to support the spirit of community they wanted to create (Bell, 1999).

Bread and Puppet, among many others, have used puppets as tools for community building, and as tools for protest. Puppets have a unique freedom to speak when people can't, and there is something about the uncanny nature of puppets that is somehow inherently subversive. The Puppetista Manifesto states that puppetry "is an anarchic art, rooted in mockery, a ridiculous gesture towards the absurdity of the established order. It is the unique ability of the clown to laugh in the face of the king." (The Puppetistas 2001). The Puppetistas are a group of puppeteers that perform every year at the yearly vigil in November at Fort Benning by the 
School Of the Americas Watch group to protest the institution that trains Latin American death squad leaders and dictators.

In the protest puppetry of the Puppetistas, there is a plea for humanity. The monstrous puppets remind us of the darker side of the subject-object relation: that of subjugation, and of the human fear of being transformed into an object. In his seminal essay, Tzachi Zamir presents the myth of Sisyphus as an example of a literary manifestation of this fear (Zamir 2010). Sisyphus is reduced to an object in that he acts with no agency, eternally pushing the rock up the hill through no choice of his own. Yet he is not fully object: unlike the rock, he feels and endures the pain and tedium of his hard repetitive work. Such is the condition of many working poor, and so the call to puppetry is related to the call to give the objectified a voice. Puppetry presents the opposite of Sisyphus' fearful fate; it elevates objects into subjects rather than objectifying subjects. Or, as Gross puts it, puppetry "bring objects to life in a world where human beings make themselves into their own effigies.” (Gross 2011, pg 33) 


\section{Literature Review Summary}

In this review, I looked at the uncanny in electronic art, figurative sculpture, social robotics, and puppetry. The review on social robotics examined the underlying causes of uncanny feelings evoked by human representation. The uncanny valley is usually avoided when designing social robots. On the other hand, in figurative art and in puppetry, it is often embraced, and it is used as a tool to create a space for reflection and for socio-political criticism. A brief survey of puppetry and of some figurative artists showed that the figurative form and the uncanny function as an effective and influential visual language. 


\section{PART 3: GOALS, METHODOLOGY, AND SENSIBILITY}

\section{Project Objectives And Research Questions}

\section{Project goals:}

- To create human-sized characters positioned within the space of the viewers.

- To disturb the boundary between the art and the viewer, and between subject and object.

- To create sculptural works that integrate elements and methods from puppetry and from robotics, which reflect on the ideas of presence and the uncanny.

- To create uncanny yet socially pleasurable experiences.

\section{Research Questions:}

- What elements push an object toward forming a sentient identity?

- What visual elements evoke empathy for an object?

- What pushes an object towards or away from the aesthetically unpleasant aspects of the uncanny valley? 


\section{Methodology}

Practice-based research is most clearly articulated through systematic documentation of studio practice. Art studio documentation reveals reflexive methodologies that employ analytical and critical thinking skills

(De Freitas 2002). Artist Gert Germeraad exemplifies the type of reflexive methodology with a detailed and personal presentation of his own artistic process published in the Journal for Artistic Research (Germeraad 2013). Clear documentation and a transparent description of the artistic process also help fold the concept of rigor into artistic scholarship (Biggs and Büchler 2007). "Rigor in research is the strength of the chain of reasoning, and that has to be judged in the context of the question and the answer" (Biggs and Büchler 2007). It follows that detailed documentation of studio practices allow for the work's rigor to be clearly evaluated.

In my own work, I employ an action research and a reflexive methodology to work towards the project objectives listed above. I produce some work, reflect on it and make observations, and then I apply these reflections and observations to subsequent works. Following the Germeraad's example, I present my process, my actions, and my thoughts as honestly as possible (Germaeradd 2007). I apply rigor by transparently evaluating my work against the objectives, and reflecting on the research questions during the 
creation process. I use the questions as points around which to center my observations and reflections.

Another methodology I engage is the style of participatory action used by puppetry troupes such as 'Bread and Puppet', whereby viewers are invited to directly interact and engage with the work, and whereby the presence of the object creates a temporary community (Kourilsky 1974; Falk 1977; Bell 1987; Bell 1994; Bell 1999). In each of my works, there is some participatory element, whether it's an invitation to pull on a marionette's string, or an invitation to 'play' with a life-sized doll, or response to the viewer from the artwork itself (triggered by a sensor). Each of these is explained as it applies in the 'Results' section of this thesis.

In the 'Artistic Outcomes' section I present the process of making one figure, one character, at a time; with each character, I test out building, performance, and participatory techniques, while contemplating my research questions. From puppetry, I take the premise that engaging the viewer with the work as a relatable character, rather than a thing, breathes life into the object. So, I refer to my works as my "people", and each work follows the naming conventions applied to people, with a first and last name; they share my last name because I am their creator, their parent 
and caregiver. Naming the works as such is a manner in which to instigate 'play' with the viewer: it is an invitation for the viewer to engage with my "people" as something other/more than an object.

\section{A note on Camp}

In addition to methodologies, artists also brings their sensibilities - or tastes - to their work. An artistic investigation cannot, by its nature, be an objective investigation. Artists necessarily infuse their tastes within the work, and as part of a reflexive methodology, I must disclose and examine my own sensibilities. I have a strong affinity for the sensibility known as 'Camp'. The quintessential example of Camp is the drag queen aesthetic, which with its high degree of stylization, "is an autonomous fashion phenomenon...[that]... took its cue, not from the streets but from the stage, from the gaudy, over-dressed fashions of the actresses and singers who starred in minstrel shows and vaudeville.” (Harris 1995, pg 63) Indeed, Susan Sontag, in a first attempt at describing Camp notes that it is a sensibility that theatricalizes experience and that refuses seriousness (Sontag 1964). "The whole point of Camp is to dethrone the serious. Camp is playful, anti-serious. More precisely, Camp involves a new, more complex relation to "the serious". One can be serious about the frivolous, frivolous about the serious" (Sontag 1964, page 8). In fact, Sontag notes 
that from a "serious" point of view, many examples of Camp appear as either bad art or kitsch.

"Camp taste turns its back on the good-bad axis of ordinary aesthetic judgment. Camp doesn't reverse things. It doesn't argue that the good is bad, or the bad is good. What it does is to offer for art (and life) a different - a supplementary - set of standards." (Sontag 1964, page 7) "The way of Camp is not in terms of beauty, but in terms of the degree of artifice, of stylization” (Sontag 1964, page 2).

The strong engagement with artifice makes a Camp sensibility particularly suited for this artistic investigation into creating artificial "people". In Camp, artifice is taken to the extent that there is a convertibility of "person" and "thing" (Sontag 1964). The existential nature of my "people" as fake creatures unavoidably gives them a Camp sensibility, and my aesthetic inclination towards a tongue-in-cheek extravagance bolsters their Campiness. Camp "is the love of the exaggerated, the "off", of thingsbeing-what-they-are-not” (Sontag 1964, page 3).

A Camp sensibility is also well suited for my purposes of creating 'characters'. "Camp is the glorification of 'character'... [, where]...character is understood as a state of continual incandescence - a person being one, 
very intense thing" (Sontag 1964, page 6). While Sontag in her essay is referring to big-screen iconic characters such as Greta Garbo, and possibly to the personas drag queens take on, I think this idea of Camp "character" can be easily extended to puppets, to cartoon characters, and to the creatures that I am creating. Camp celebrates two-dimensional artificial personas; camp "character" is that which can be characterized by a catch phrase. In the spirit of Camp, I give each of my characters a catch phrase descriptor, and I make no pretense of my characters having any depth beyond their performative ticks, their awkwardness, and the ambiguity of their descriptors. This is not to dismiss the depths of human nature, but rather it is a distillation and isolation of individual (and sometimes unsightly) moments in the human condition. Camp taste is a "love for human nature. It relishes, rather than judges, the little triumphs and awkward intensities of “character"”(Sontag 1964, page 10).

Sontag equates an appreciation of camp with an appreciation for the arts of the masses (Sontag 1964). Art of the masses, or folk art, is significant from the pragmatist view of aesthetics I want to take. I fold in aspects of folk art, and popular art into my work by drawing from the art of puppetry, but also by using a Camp sensibility, whereby the goal of showing the work is not to transmit content (as Camp is all about style not content), but to 
create an experience, to entertain, and to make people smile. This is not to say that my work is devoid of content, but that I hope a viewer can enjoy a complete experience of my work without feeling the need to analyze its meaning. "Camp sensibility is one that is alive to a double sense in which some things can be taken. But this is not the familiar split-level construction of a literal meaning, on the one hand, and a symbolic meaning, on the other. It is the difference, rather, between the thing as meaning something, anything, and the thing as pure artifice" (Sontag 1964, page 4).

Perhaps it is also appropriate for me to explain my particular affinity for camp, as much as anyone can explain her personal tastes. Sontag accurately describes the Camp sensibility when she says "the ultimate Camp statement [is] it's good because it's awful" (Sontag 1964, page 10, emphasis hers). While on a superficial level, this statement describes the visceral titillation that Camp imparts, something deeper happens when the "awful" is embraced: the outsider appropriates their status. Camp sensibility is in many ways the outsider's sensibility. For example, it is well known that "homosexuals, by and large, constitute the vanguard and the most articulate audience - of Camp" (Sontag 1964, page 9), with the quintessential example of Camp being the drag queen. Despite my cis- 
gendered heterosexual orientation, I have always had a strong identification with the queer community, as someone who was a fellow outsider, bullied by peers and mistreated by teachers.

Perhaps one of the most poignant examples of Camp's fun extravagance set against the backdrop of outsider sadness is Paris is Burning (1990), a documentary about drag balls in New York city in the 1980s, and about the people involved in the scene. The film gives an insight into the difficulties of their lives, but also a view of a vibrant underground culture. The drag balls were elaborate pageant-like contests in which the contestants were judged for their style and dancing abilities, according to aesthetic standards that followed (and made) the edicts of Camp.

It's been over fifty years since Sontag penned her Notes on Camp, and twenty-five years since Paris is Burning, and the queer community continues to vanguard Camp aesthetics. Rupaul's Drag Race (2009ongoing), a reality TV show in which Drag Queens compete for a crown (strongly influenced by Paris is Burning), is an excellent example of contemporary Camp. While the show is for the most part intentionally silly and relishes its own tackiness, there are many poignant moments in which the contestants share the deep difficulties in their lives and the pain 
of rejection from their families. There is one moment (in season 5) in which Rupaul tells her 'girls': "we as gay people get to choose our family", and this had a very deep resonance with me. My parents were refugees, had to leave their entire families behind, and didn't have the means, until it was too late, to give me siblings; so, I grew up without knowing a family other than my mother and father. I too, in my life, got to choose my family. And now, here, with this project, in some way, I get to make my family. 


\section{PART 4: RESULTS AND OUTCOMES}

\section{My Cast of Uncanny Characters}

Here I present each of my artistic outcomes as a cast of characters, which includes myself. I start with a description of how I fit into the artwork and place myself within it, and then I introduce each of my creations. Suzana Jofre is the first of the series, cast out of duct-tape, using my body as a model. She is perhaps the most glamorous of the lot. I then made Joana Jofre, using the same duct-tape casting technique, and a copy of the same face. However, Joana exudes an entirely different personality than Suzana, as her face is painted differently, her style of dress is different, and she is stuffed with softer and lighter materials. Both Suzana and Joana were used as large marionettes in performances, but Joana in particular (because of her light weight and flexibility) was used in public interventions. Little Furry Beast Jofre is the only non-anthropomorphic character in the family, which I made to evaluate the importance of the human form in generating the uncanny and in establishing relatability. Monster Jofre returns to the human form, but with sufficient deviations as to make her a decidedly non-human creature. Monster Jofre was the piece that underwent the most experimentation and transformations as I 
explored different looks for the character. Sound Bust Jofre was created to explore a strictly sculptural (as opposed to puppet-like) direction; it is a bust with no moving parts, and uses only sound to interact with the viewer. Fuzzy Jofre is the final work I built in the series, and it borrows elements from each of the different works in the series; she has the same face as Suzana and Joana, but made out of different materials with different texturing and coloring, and like Monster Jofre, she is not categorically human.

\section{Ana Jofre}

Ana Jofre will polish the shards of your broken heart with the hopeful fervor of someone who knows how to make you smile.

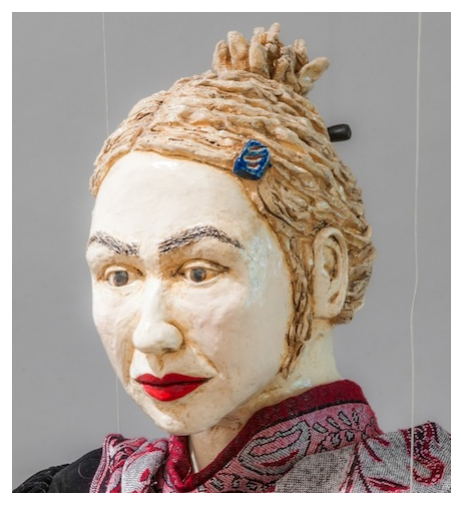

Figure 2: Ceramic self-portrait, 2013 
I place myself among this body of work as performer and as matriarch of this collection of creatures, of my "people".

Most of my "people" are copies of myself in one way or another. This was, at first, on a conscious level completely unintentional. I happened to have the self-portrait shown in figure 3 with me, and because I wanted to learn to work with digital $3 \mathrm{~d}$ scans, I scanned the face of this sculpture as something to experiment with. It then occurred to me to use this copy of the sculpture's face on other figures. I made bodies with copies of the same face for two explicit reasons: 1) to visually explore how the uncanny, as Freud had suggested, can arise from the double (Freud 1926), and 2) to make a material inquiry into the extent to which copies can differ from one another. But the fact that the repeated face is unequivocally mine cannot be brushed aside. Furthermore, I make performative appearances throughout my work. It seems I have included myself within the cast of characters I created; I have dispatched a part of myself into their world, to stand alongside them.

With the inclusion of myself in the works, I have incorporated methodologies that integrate speculative play into my practice (Grocott 2003). Discovery through play, also known as ludic methods, have 
become in recent decades an established method for creative practice and also for research (Philpott 2013). Bringing myself into the works came out of playful exploration, from the literal play of pulling on marionette strings and performing with them, to the metaphorical frolic with a funhousemirror of self-reflection.

Arguably, what artists offer the world are themselves: the artistic process is necessarily (though not always overtly) self-revelatory in one way or another; the artist hands over a piece of themselves to the audience in one way or another. So, here I am, in one way or another.

\section{Suzana Jofre}

Suzana Jofre's flamboyance busted the seams of every disguise.

\section{The Building process: part 1}

Suzana Jofre is the first work I started producing in this project series. Up until this time, I had worked mostly in ceramics, and I had devoted my undergraduate studies in art to improving my modeling techniques. However, my interest in kinetics and in public accessibility demanded that I use lighter and less fragile materials, and I entered the interdisciplinary program with a desire to develop new sculptural techniques. I was 
specifically interested in building techniques that were accessible with everyday type of objects, as a matter of methodology, following the examples of puppetry troupes such as the Puppetistas and Bread and Puppet Theater in which simplicity in materials and props are both a matter of principle and aesthetic (Brecht 1970, pg 44-46). So, this first sculpture is based on a body cast made out of duct tape. I had myself wrapped up in duct tape, then cut myself out, then re-taped the shell and stuffed it with futon stuffing and expandable spray foam. (Instructions can be viewed here: http://youtu.be/5i7YhYMwpbc.) This was an effective and facile method of building a full body form in correct proportion.

Housing the work in an open multi-user studio allowed for the work to be seen by (and interact with) viewers during its production. As the body parts took human form, the work would sometimes startle people when they saw it out of the corner of their eye. I took this as an early sign that it was already serving its purpose as uncanny.

The bulk of character-creation, however, occurred through the process of choosing her clothing and hair. I chose a flamboyant style of dress to underline the performative aspect of the puppet, with a glam aesthetic because "the hallmark of Camp is the spirit of extravagance." (Sontag 
1964, page 5). Suzana's style of dress comes straight out of the canon Sontag defined for camp, which includes “women's clothes of the twenties (feather boas, fringed and beaded dresses, etc.)” (Sontag 1964, page 2), and short bangs.

I left the face artificially white, in part to reference the artificially heavy make-up of glam, but also to allude to Suzana Jofre's own artificial nature (is it less uncanny if it doesn't try to 'fool' us?). I also used intentionally visible and decorative strings to directly state her marionette nature.

The face was based on the digital scan of the ceramic self-portrait that I had made prior to arriving at OCAD, shown in figure 2. The scan was used to digitally create a mask form with those specific facial features, and the mask was physically rendered by means of rapid prototyping. I noticed, when I appended the painted mask, that the face was the most crucial element in the process of transforming the work from an inanimate object into a life-like character. It didn't seem to fully convey personality until it had a face. 
The first version of Suzana Jofre is shown in figure 4. She is a 6-foot tall marionette with articulation at her head, shoulders, elbows, wrists, and knees.

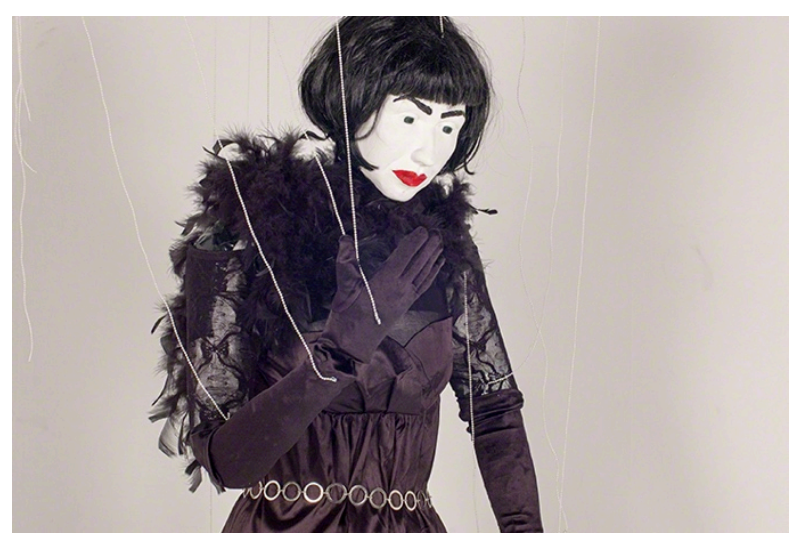

Figure 3: Suzana Jofre (2013) (Photograph 2014 by Kris Brandhagen)

\section{Performances}

Suzana Jofre was strung up, despite her large size, as a conventional classic marionette, with string controlling her arm movements. The strings were strung around pulleys hung from the suspension framework from which she hangs. Pulling on the strings actuated her arm movements. It was a cumbersome system, although having me pull on the strings made for a compelling performance aesthetic, as shown in figure 4, in part because the mechanism is so obscure. 


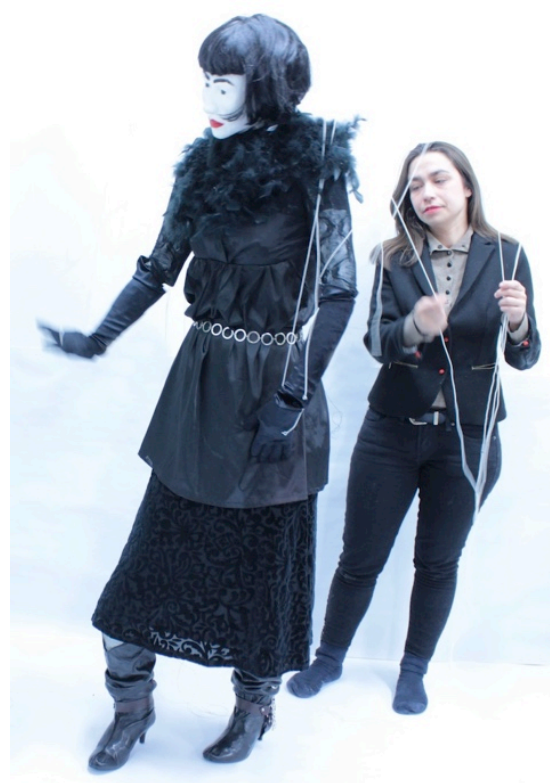

Figure 4: Performing with Suzana (2014)

I made an animated GIF of Suzana smoking a long cigarette (figure 6) (it can be viewed at this link:

\section{http://onewomancaravan.net/images/People/smoking-suzana.gif ).}

Upon viewing it, I decided that this repetitive compulsive motion should be automated for live performance, and that this would be her trademark character tick; the performative and repetitive behavior that completes her 'character'. A repetitive behavior reinforces the two dimensionality of a campy 'character', but this also alludes to Judith Butler's theory of performativity because the repetition of an act is constructing Suzana's identity. Butler's theory of performativity is specific to the gender aspect in identity. Butler posits that gender is performed: it is constructed by a 
repetition of acts deemed to belong to one gender category or another (Butler 1993, 2006). Butler specifically uses the example of drag queens to demonstrate how gender is performed (Butler 2006). Suzana Jofre is performing female, the way a drag queen performs 'female'.

Animated GIFs, as a medium, seem particularly suited to my work because they capture the repetitive artificial nature of my people. Also, it should be noted that GIFs on the Internet comprise a significant portion of the canon of contemporary Camp.

For the IAMD group show in the spring of 2014 (Done Being Wrong), I automated Suzana's smoking motion, but I also added an element of interactivity by leaving some of the strings open for the audience to pull. This installation was generally successful, in that people were very eager to interact with her and pull her strings. The automated motion was programed such that it was very slow and subtle, and while I liked the effect it had on some people who seemed startled when they finally noticed that she did move on her own, I prefer this particular smoking motion to be more obvious and emphatic. 


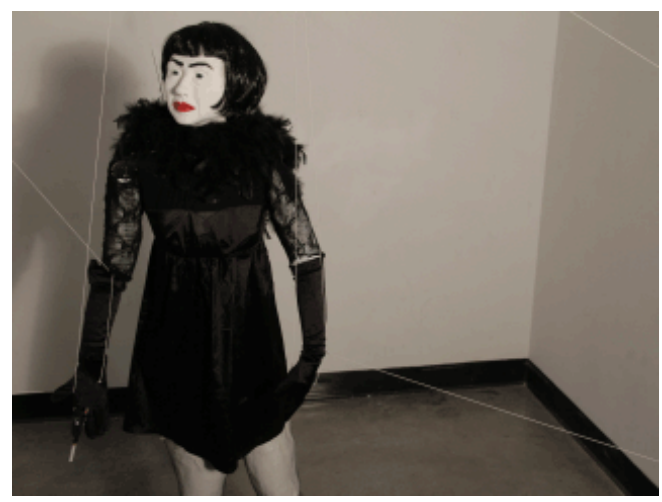

Figure 5: Smoking Suzana (2013) (Photography by Adrian Phillips)

Suzana Jofre's face is a copy of a self-portrait of mine, thus, I'm visually experimenting with the Freud's idea of the double, and also with making copies. According to Freud, the double is a cause for uncanny feelings because of its relation to the effigy - it is a harbinger of death (Freud 1919). I tried playing with this theme visually and performatively, experimenting with the presentation and performance of all three copies, by creating short experimental films that starred, Suzana, the original ceramic sculpture, and myself. One result of this experimentation can be viewed here: https://www.youtube.com/watch?v=BYioflgLawQ. This film was made as intentionally 'lo-fi' as possible, with an intentional graininess and choppiness, in line with my taste for Camp. It is both ridiculous and melancholic, with a simple (yet somewhat ambiguous) narrative. However, because of the roughness of the images, it's hard to evaluate the effect of the double. 
A better feel for the uncanniness of the double can be seen in the photograph shown in figure 7, where I am shown with Suzana Jofre and with the original ceramic self-portrait sculpture placed in a wheelchair, which gave it a strangely human element. This photograph is absolutely absurd and uncomfortably awkward (in a strange room with bad lighting and all), yet in the spirit of Camp, I'm really compelled by its very weirdness. It is better (or worse if not seen a Camp perspective) in GIF form, as seen here: http://onewomancaravan.net/SuzanaAnaMe.gif.

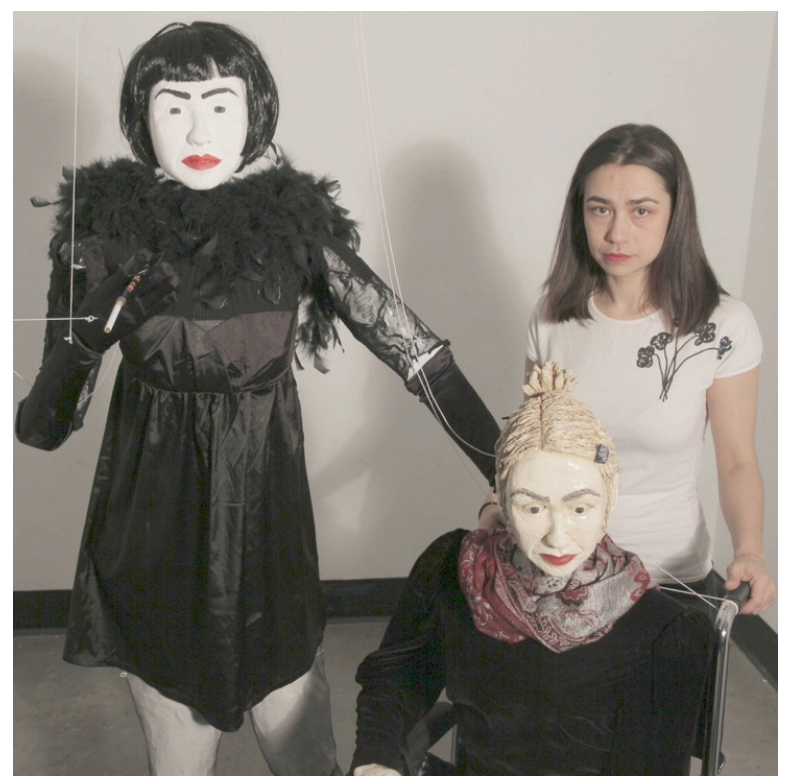

Figure 6: Suzana, Ana, and Ana (2013) (Photography by Adrian Phillips) 


\section{Building Part 2: Addition of legs}

I decided to give Suzana an extra pair of legs to push her even further away from human-ness. Does this make her more or less unsettling? Does it make her more interesting? In the final thesis show, she is set up such as to be smoking. Is it this compulsive vice that dehumanizes her, or is it the extra legs? Or were the artificially white face and the accented marionette strings sufficient to pull her out of the human realm?

Because the artificial face and the visible marionette strings are strong visual cues that draw her away from being human, she is not uncanny in Jentsch's sense of the word as she does not evoke uncertainty about her existential status. Without the extra legs she is not particularly unsettling, but perhaps maintaining a fully human form may make her less visually interesting. Some feedback I received questioned the literalness of her form. Since she is already not fully human, then there is no justification for such literalness in her rendering. I was not exploring the full sculptural parameter space. Also, I realized that in the aesthetics of puppetry, the best characters do not adhere to parameters of a literal human body (see Jim Henson, for example). 
Why add more legs? This decision is in part out of practicality: I wanted her to stand on her own rather than to have to suspend her. The futon stuffing I used for her body is too heavy to keep her center of mass sufficiently low for her to stand sturdily on two feet. Another reason I chose to give her four legs is because we attach much of our humanity to our two-leggedness; I think a four-legged person contradicts this attachment and invites the uncanny.

\section{Joana Jofre}

Joana Jofre suspends disbelief on your coatrack.

\section{Description}

Joana is the second full size sculpture made in this series. It is made using the same duct-tape casting technique I used to make Suzana. It is stuffed with light soft plush filling (rather than the heavy futon filling), and also with light plastic bags. So, her materiality has a soft-sculpture feel. I made her over the 2013-14 winter holidays - I wanted another quick figure to experiment with for the winter 2014 semester. I printed another rapid prototype of the facemask I used for Suzana. I used the same face because 
I wanted to continue exploring the uncanny in the double, and because I wanted to explore the extent to which a copies can differ from one another.

Joana Jofre, shown in figure 8 , is a 5 -foot tall figure with articulation at her head, shoulders, elbows, wrists, hips, and knees. Her face is painted naturalistically, so as to be more likely to 'pass' as a human than Suzana. However, I decided to dress her in ridiculous naively outlandish and unfashionable clothing, to underline the idea of her as an outsider; but also as another nod to Camp aesthetics (Sontag 1964). Beyond campy, her fashion choices are actually ugly, and I chose unfashionable attire to reference some aspects of puppetry: "Puppets are intentionally ugly against the glittery status quo," (The Puppetistas 2001)

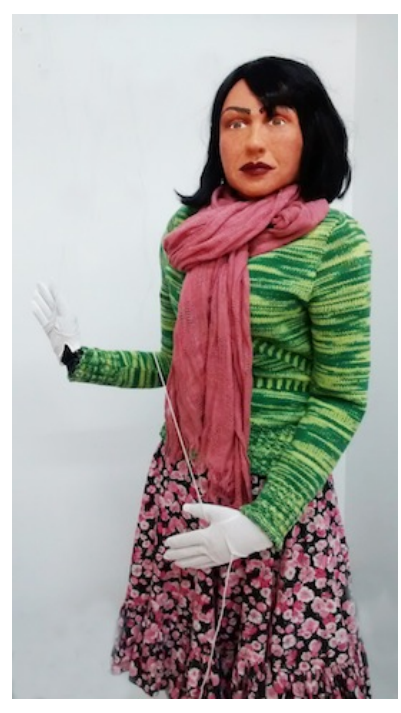

Figure 7: Joana Jofre (2014) 


\section{Public Experiments}

I inserted Joana Jofre into some everyday scenarios with people to see how the uncanny can function as an interrupter of the mundane to create playful situations. In these experiments, I incorporate methods of participatory action in the spirit of 'Bread and Puppet' theatre, whereby the viewer's engagement with the work becomes part of the artwork, by becoming part of the performance (Kourilsky 1974; Falk 1977; Bell 1987; Bell 1994; Bell 1999).

In the IAMD studio

I mounted Joana along with Suzana in an open part of the IAMD (Interdisciplinary Arts Media and Design) studio, and found that their presence created playful situations. Figures 9 and 10 show colleague and classmate Pilar Fernandez-Davila Zariquiey taking selfies with the ladies. 

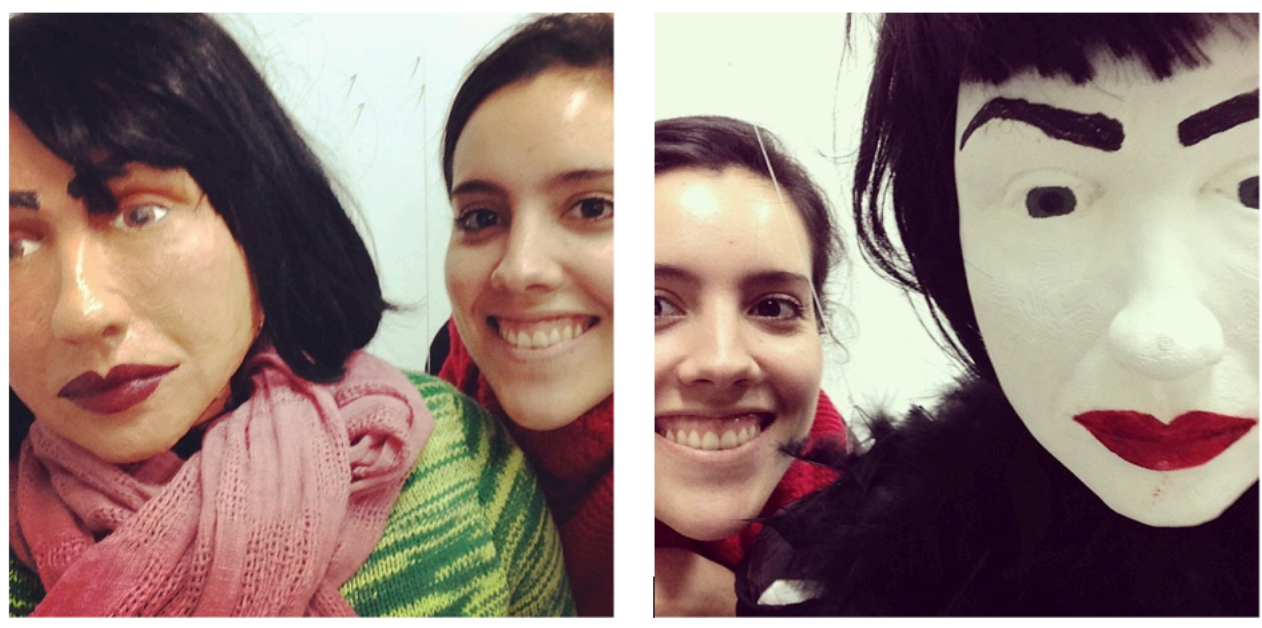

Figure 8: Pilar taking a selfies with Joana (left) and Suzana (right) (2014)

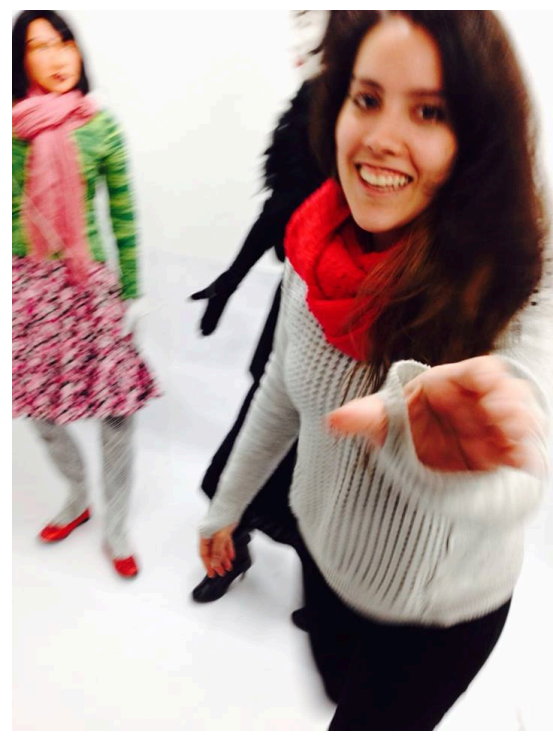

Figure 9: Pilar and the Papparatzi (2014) 
At the Gladstone Hotel Café

In January 2014, I installed Joana Jofre at the Gladstone hotel café as part of the Come Up To My Room event (figure 11). I sat her at the bar so that she blended in as much as possible, and the bartenders played along by serving her a drink at the bar. I enjoyed the startled and amused reactions people had when they encountered her. Countless people started asking her if the seat next to her was taken only to break down into incredulous laughter when they realized Joana's true nature. One viewer I chatted with said that she had been looking at Joana from afar for some time, thinking, 'she's weird' and 'what's wrong with her', only to encounter up close, exactly what was 'wrong' with her. In another incident, a mentally ill individual sat next to Joana and had a very long conversation with her. At one point, perhaps frustrated by Joana's non-responsiveness, this individual tried to give Joana CPR. That spectacle occurred during the press preview of the show, and it unfortunately (maybe fortunately) seemed that the people interviewing me believed that the scene was part of a performance I was putting on with my sculptures.

The day after the opening night party, I found Joana completely disheveled. One of her gloves was missing, as was her hair barrette. Her 
wig had been torn off and was sitting loosely on her head. I asked the bar tenders if they knew what had happened to her, and they laughed and said she's lucky to be in one piece. When I asked for further explanation they told me to imagine 200 very drunk people all realizing at the same time that she wasn't real. I wished I had witnessed it, and note that I should probably leave cameras up to document interactions with people. Taken as a performance experiment, this work exposes a side of human nature similar to that exposed by Yoko Ono's Cut Piece (1965), or Marina Abramovićs Rhythm o (1974). In Abramović's work, people became aggressive and violent, until she stood up to confront them (at which point they ran away from her). Joana couldn't stand up to confront the drunken gang, and with no one advocating for her, she was almost torn apart.

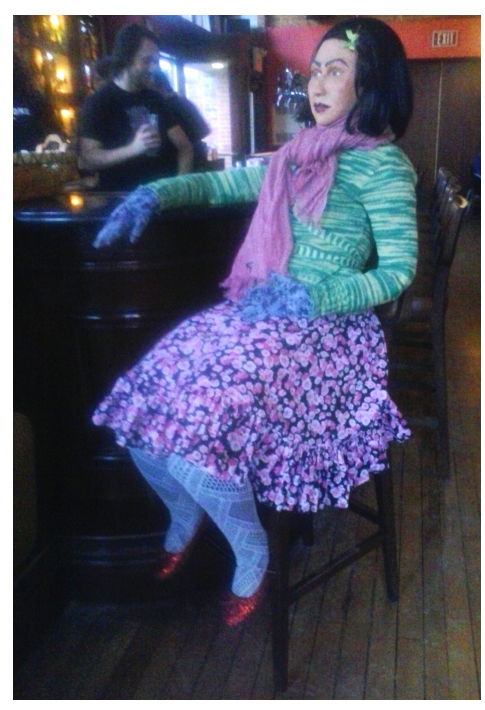

Figure 10: Joana Jofre at the Gladstone Hotel Cafe (January 2014) 
At Grange Park

As part of a workshop led by Martha Ladly entitled "People, Places, and Things" at the 2014 Mobile HCI conference, we were encouraged to use our mobile GPS devices along with our cameras and google maps to create a narrative. I decided to use this opportunity to take Joana out to the park. People on the street who saw me carry her around looked startled at first sight, but people were also very willing to 'play' with her. Figures 12 and 14 show a couple of examples of such play. In one photo, a man engages her in conversation on a park bench, offering her a piece of his chocolate bar, in the other, a woman poses for a selfie with Joana.

I observe that the compulsion to take photographs of oneself amid dolls is a universal way in which people 'play' with them (See for example Grow 2014). I had the opportunity to visit the Dubai museum, where there were life sized dioramas depicting life in Dubai at various points in history, with life sized mannequins involved in various activities and scenarios. It was interesting for me, in the context of this work, to notice that most museum visitors stopped to take photos of each other with the mannequins, posing next to them, as part of the scene and situation. 


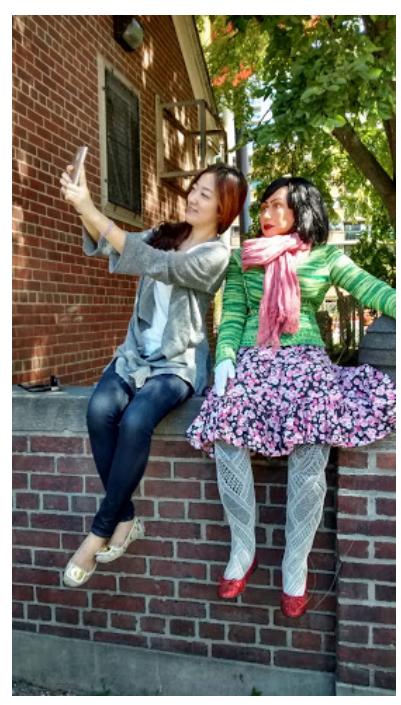

Figure 11: Viewer at Grange park takes a selfie with Joana (2014) (Photography by Bryn Ludlow)

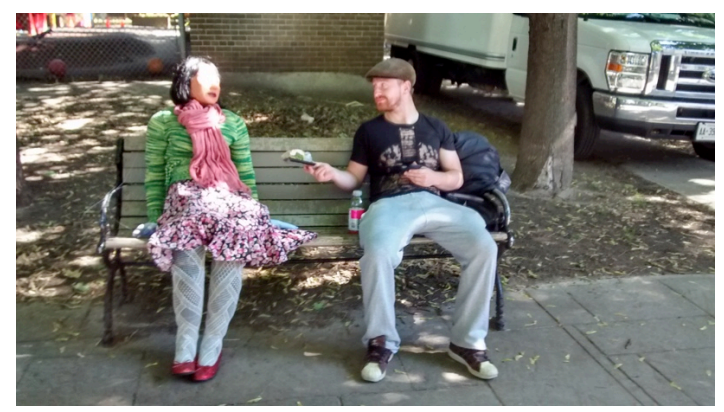

Figure 12: Viewer at Grange park engages Joana in conversation (2014) (Photography by Bryn Ludlow)

I enjoy creating these situations that enable play and social interaction. I wonder if a toy animal would have the same effect in public spaces as a fake human? I speculate that probably not, because it doesn't have the same level of uncanniness. If the uncanny is about the exposition of a repressed fear, then it seems those fears may be better represented on a 
human. If the uncanny is about psychic uncertainty, then a fake human has a better chance of creating a confounding situation than a fake animal.

The fact that this humanoid object was capable of creating playful and socially engaging situations is interestingly consistent with the studies on social robots that found their presence to increase social interactions among humans (Robins et al. 2008; Robins et al. 2013; Kidd et al. 2006).

The performance that introduces the object into the public space is an important part of what enables these playful experiences. Carrying Joana around, pushing her on a wheeled chair, setting her down and adjusting her posture and clothing was part of the performance at the park. A viewer who had done extensive caregiving told me it reminded her of her caregiving work, and that watching my gentle ministrations and accommodations made her feel empathy for Joana.

\section{Paired with Suzana}

I paired Joana with Suzana in the studio installation I made in the winter of 2014, and I made some films of the two interacting in conversation (figure 14). Neither the film (which can be viewed here:

http://youtu.be/FWQPWaWv-28), nor the conversation narrative was 
particularly successful, perhaps because it tried a little too hard to be 'campy'. Sontag suggests that "Camp which knows itself to be Camp ("camping") is usually less satisfying" (Sontag 1964, page 4), and she states that "probably, intending to be campy is always harmful" (Sontag 1964, page 4). However, it was interesting to see how through their clothes and movements, they were completely differentiated from one another to the extent that it wasn't immediately obvious that they had the same face. And I did create a couple GIF moments from the film that were satisfyingly ridiculous (from the point of view of one who relishes Camp):

http://onewomancaravan.net/images/People/conversation-1.gif and http://onewomancaravan.net/images/People/conversation-2.gif

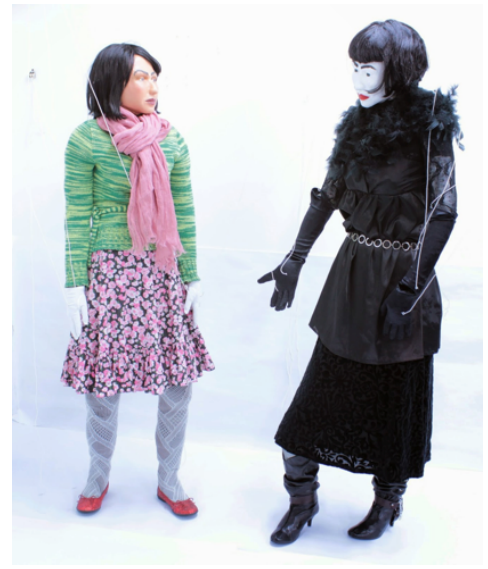

Figure 13: Joana with Suzana (Still from 'The Long Walk Home' 2014) 


\section{Final Installation}

For the final installation in the thesis exhibition, I changed Joana's clothes, to allow her to better fit in as a human, so that a gallery viewer may at first glance take her for granted. Figure 15 shows her in her new attire, sitting at the table, tapping her hand. While the string that actuates the hand motion is very subtle, it is wrapped around a visibly exposed pulley to intentionally break the illusion.

I believe that some element of repetitive motion is crucial for all my works, and so I refer to them as minimal robots since they each possess the minimum amount of autonomous motion to render a temporary illusion of lifelikeness. The motion I ascribe to Joana Jofre is a hand impassively tapping a table. While this motion is minimal, it implies a narrative arc that she is waiting for something, and it gives her an emotion of impatience despite her neutral facial expression. (Joanna tapping the table can be viewed here

\section{http://onewomancaravan.net/images/newer/joana.gif and here} https://www.youtube.com/watch?v=XoUNRGqnjr4). Joana's repetitive hand tapping is an example of a singularity that defines character, and such singularities are specific to Camp "character" (Sontag 1964). This 
simple repeated behavior transforms her from a mutable stand-in into the lady who is waiting, maybe even the one who is impatient but also impassive.

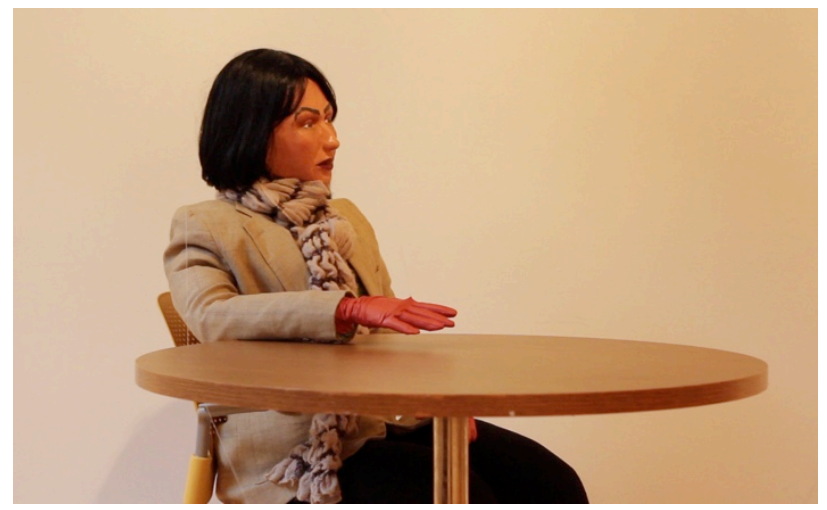

Figure 14: Joana hand tap (2014) (Photography by Juan Bonilla)

\section{Little Beast Jofre}

Little Beast Jofre was wedged deep into the day you tore thunderbolts out of the clouds.

Some feedback I received from my colloquium encouraged me to explore directions beyond the human form. So I created an abstracted furry creature that exhibits a simple breathing motion. Its rate of breathing changes as viewers approach it, such that it starts breathing faster as the 
viewer gets close (http://youtu.be/GzJFIzyArt4). Viewers responded to this work with empathy as it evokes the illusion of a furry little creature. One viewer, while she sat on the floor petting it (shown in figure 16), noted that it reminded her of Descartes' conception of the animal. I think that Little Beast's 'cuteness' combined with its mechanistic nature makes it uncanny: in realizing that it is a machine, the viewer feels that the empathy evoked by its 'cuteness' has been misplaced somehow. But because it is not human, nor does it anatomically reference any particular creature, the little furry beast does not have the same unsettling quality as my humanoid creatures.

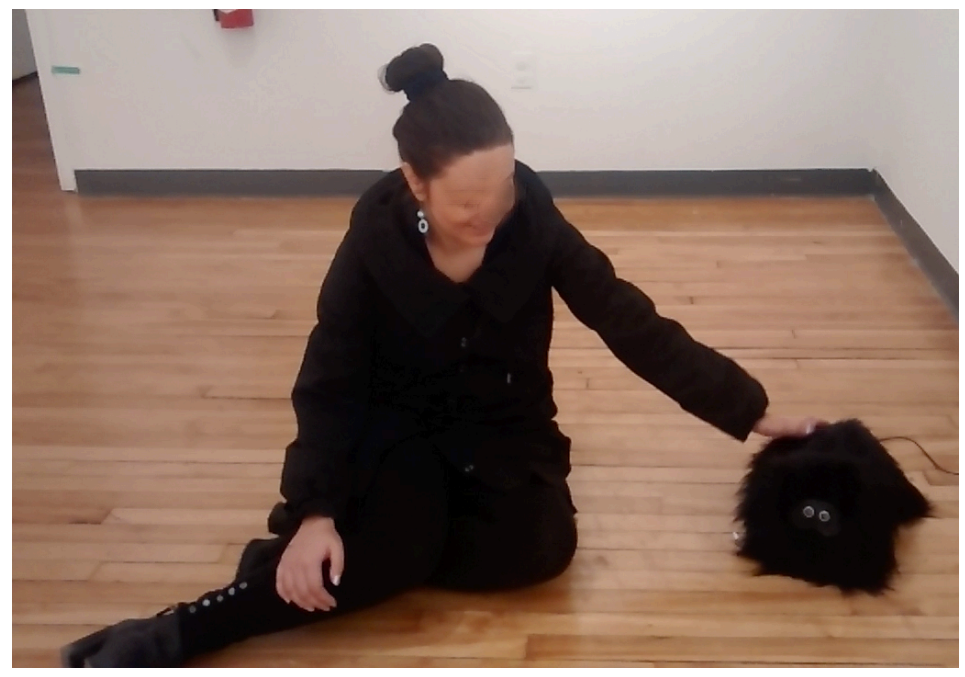

Figure 15: Viewer petting the Little Furry Beast (2014)

In the final thesis exhibition, there are a few little furry beasts, and one of these little furry creatures is attached to a Roomba (a robot vacuum 
cleaner that navigates the room with sensors), so that it moves about the room to interact with viewers.

While the most vociferous opinions during my colloquium discussion persuaded a move away from the human form, some approached me after the colloquium to encourage me to stick with the human form. One person in particular argued that I should not be discouraged by people's discomfort with my uncanny creatures, because the uncanny is a significant means by which to interrogate notions of normality. This was an important reminder. So, I decided to continue working with the uncanny in the human form because of its potential to create a cognitive dissonance that may lead to one to question one's assumptions, and because I want my works to instigate contemplation specifically about the human (and post-human) condition.

\section{Monster Jofre}

Monster Jofre has a secret continent that drift around your island, quietly collecting all the spoons you throw into the ocean.

The final form of this work, shown in figure 19, which I eventually named 'Monster Jofre', is intended to interrogate our assumptions of femininity; and also to evoke the uncanny, in Jentsch's sense, by straddling the line 
between creature and costume. This work went through many different incarnations before it settled into its final form.

\section{Technical details on the skeleton}

The starting point was a digital model of a ball-jointed wooden sketching mannequin. The digital model was divided into parts; the parts were digitally sliced and placed within a 24 " by 96 " by 2 " volume corresponding to a sheet of rigid insulating foam, out of which they were physically cut by $\mathrm{CNC}$ milling. The $\mathrm{CNC}$ milled parts were glued and assembled into a life-sized sketching mannequin. Unfortunately, the digital mannequin's proportions, while looking ok on the screen, did not look accurate when it was physically realized. The resulting figure was reproportioned to fit women's clothing, and was balanced with weights on its feet such that it stands on its own. I also had to make the legs rigid for it to stand stably, so it is only articulated at the waist, shoulders, neck, elbows and wrists. Figure 17 shows the $\mathrm{CNC}$ milled parts, as well as the assembled and re-proportioned skeleton. A detailed account of the project's technical process and outcomes can be found here:

http://buildingabwo.blogspot.ca/. 

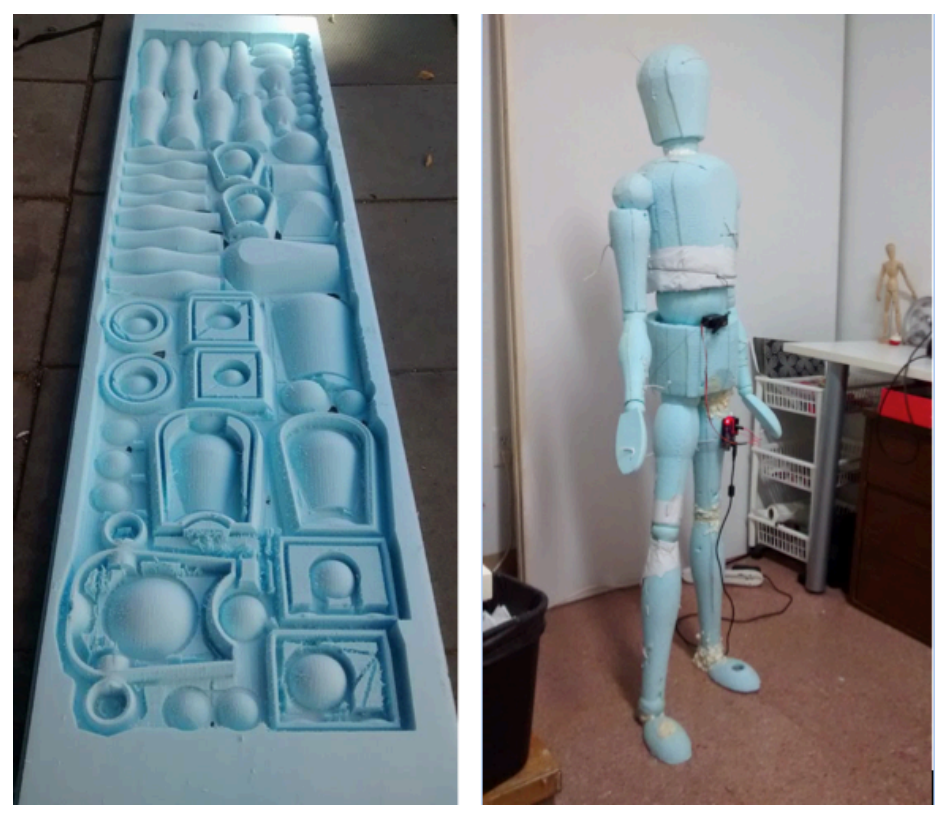

Figure 16: Left - CNC carved parts, Right - assembled figure

I incorporated two types of automated motion into the figure: one simple repetitive motion when the figure is idle, and one response motion that occurs in reaction to the viewer. The repetitive motion I chose to invoke in this figure was breathing, which was an idea inspired by my studies in puppetry: one of the lessons I learned was that the puppeteer must always remember to imply breathing in the puppet to create and maintain the illusion of life. A servo attached to the ball joint at the waist is used to move the chest up and down repetitively to simulate breathing. I think this was particularly successful, and I plan to use the method again to make future figures breathe. The other type of motion this figure features 
is a head turn that responds to the viewer; it is triggered by sensors and actuated by a stepper motor, when the viewer walks next to the figure.

In the process of working through this project, I developed a method of building human-sized freestanding figures from a digitized form, and I laid out the basic architecture of Arduino controlled servomotors for moving certain parts of the figure. The things I will do differently in the next iteration are as follows. To start, I would ensure the correct proportions by using a digital scan rather a digital model. Also, it is not worth the mill time to cut the entire body out of the insulating foam material. I can buy readymade Styrofoam balls for the ball joints, and a readymade Styrofoam head. Most importantly, I will not make the legs out of foam - as they need to be weighted down to keep the figure standing. The legs need to be constructed out of a heavier material, such as wood or metal, as a heavy bottom is required to keep the figure standing. Another consideration is that in the current model, the legs are set rigid to keep the figure standing. In future figures, I may redesign the joints in the knees and hips such that they can lock into one of various positions (I may want the figure to have the versatility to sit or stand in different postures). 


\section{Intermediate form}

My first instinct in finishing this form was to give her clothing, a wig, and a face, like I had done with the others. But because her proportions were never quite right from the beginning, this course of action turned out to be disastrous. Since the skeleton was poorly proportioned to begin with, I could never get the body quite right, and because our eyes are so sensitive to the human form, she became uncanny in a very undesirable way, in the unaesthetic way that roboticists desperately avoid. I borrowed Suzana's facemask and found that the very human face made the situation worse. I put a mask on the face to alleviate the terribleness of the situation, but, as seen in figure 18 , she looks more like a weird cheap mannequin than a sculptural work of art. In this form, it sits near the bottom of the uncanny valley, and as predicted by Mori (Mori 1970), the discomfort gets worse with animation (http://onewomancaravan.net/Breathing.gif ). I don't think this discomfort was caused by her degree of humanness, but rather by the aesthetics as predicted by Hanson (Hanson 2006). 


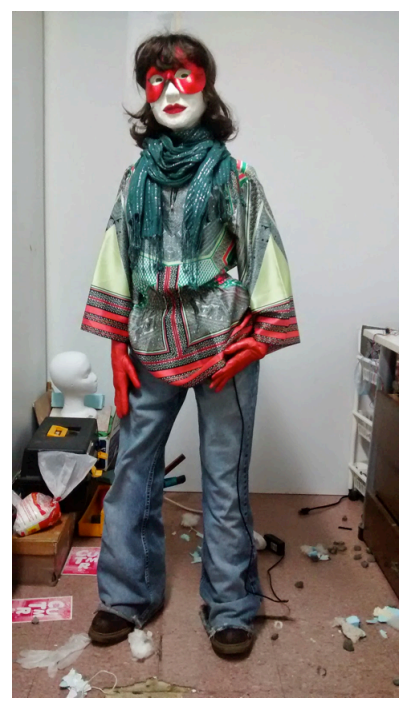

Figure 17: Intermediate form (later to become Monster Jofre) (2014)

\section{Final form}

Since the skeleton was disproportioned, I clearly couldn't make this figure ostensibly human without the disastrous results shown in figure 17 . So, I decided to abstract her upper body, while maintaining an overall humanoid form, and I named her Monster Jofre.

Monster Jofre, shown with me in Figure 18, and on her own in Figure 19, is a 5 -foot tall minimal robot that exhibits a breathing motion (her chest rises and falls), and she turns her head towards the viewer when the viewer stands next to her. Her arms are free to move at the shoulders, elbows, and wrists. 
With Monster Jofre, I explore the uncanny by means other than creating a human double. I challenge preconceived notions of the feminine by covering her body in fur, while giving her a clearly female form.

Furthermore, there is a playful ambiguity in her fur, since she is also wearing furry boots, and this implores the viewer to question whether she is a strange topless creature or a human wearing a furry costume. I have noticed that when people encounter her, they impulsively want to grab her breasts.

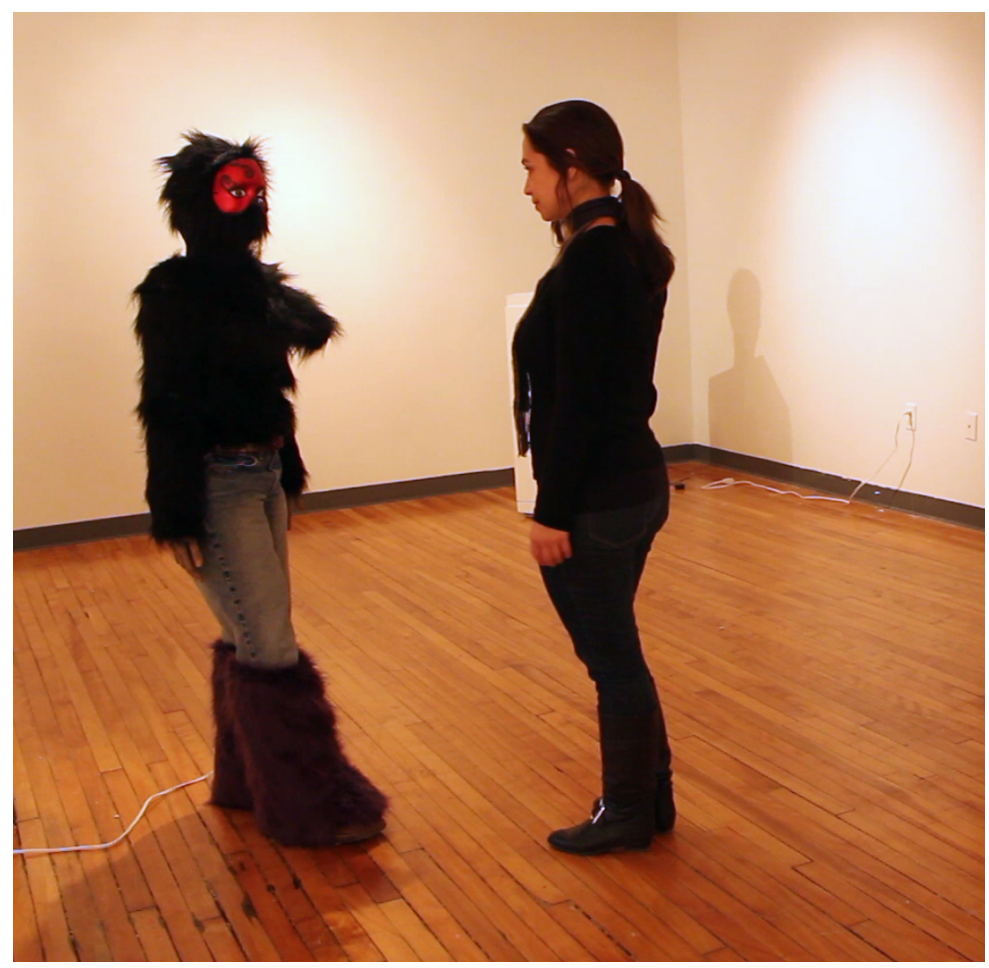

Figure 18: Me and Monster Jofre (2014) Photography: Juan Bonilla (http://youtu.be/hjzHSITy6cY) 


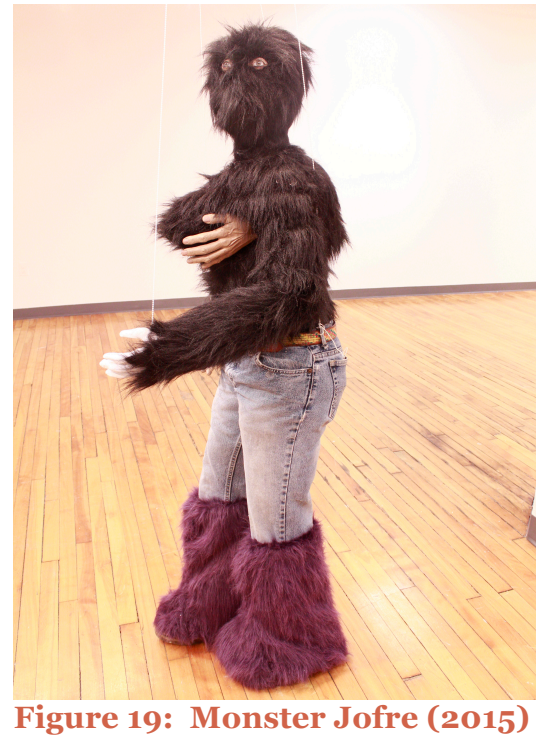

In the final installation, shown in figure 19, Monster Jofre has prosthetic human eyes, rather than painted eyes; I think the prosthetic eyes better evoke the uncanny. I also removed the stylized mask shown in figure 18, which makes her a little less cartoonish. Realism seems to play an important role in evoking pleasurable and compelling uncanny sensations. The unexpected is also an important element of the uncanny, and so Monster Jofre has a third hand that appears on her left breast. I added this extra hand because I found that almost everyone who saw her wanted to touch her furry breasts. So the hand is placed such that it appears to be holding her left breast, addressing the viewer's possibly repressed thought of wanting to touch it. 
Unlike my other humanoid works, Monster Jofre does not share my facial features, but she wears one of my old favorite pair of bellbottoms. Her body was built to fit these jeans, so she and I have similar proportions, again suggesting my presence in the works.

\section{Sound-Bust Jofre}

Sound-Bust Jofre is the unheard echo in chasm between your hopes and the sky.

I felt some frustration after having used a digital mannequin skeleton that didn't have the right proportions, since one of the reasons I had specifically wanted to use a digitally generated base was to get the right proportions in the form. Therefore, I concluded that it is probably best to use actual scanned body forms as the basis for the work, rather than digitally created forms. I mentioned this thought to my secondary advisor, who immediately gave me a demonstration of skanect software, during which he scanned a bust of me. I decided to work with this demonstration, to see how well scanned files can be physically rendered at large scale, and also to see how well the shape of the clothing translates (I was realizing at this time that using real clothing doesn't always work). Since I want to work on the life-sized scale, digital printing is not cost effective for this 
form. So, I used the CNC mill again, rendering the form out of carved Styrofoam. Again, the digital file needed to be deconstructed to fit onto a 2" thick sheet from which the parts were cut out. Once the parts were cut out, I reassembled them like a 3d jigsaw puzzle to render the bust form. Once the form was assembled, I filled in some gaps at the seams with airdry clay, and sanded it down. Then I added the details of the face and hair with air-dry clay, and painted it with oil paint. I really enjoyed this making process and was happy with the result, shown in figure 20; it has the correct proportions while maintaining the marks of the hand in the details of the face. I wish I had made a full figure using this technique because the bust shape destroys the illusion of presence that her form otherwise creates. However, I also observed that her more formal sculptural appearance (as compared to my other works) seems to evoke less interactive response from viewers (as compared to my other works).

Given the limitations of a bust, I decided to use sound instead of motion. So, I placed a sensor, an mp3 player, and a speaker inside the bust so that it emits a sound when people approach it. I tried an eerily sexualized giggle, but this fell flat at the first showing. The laugh was so unexpected and out of place that it simply didn't register for most people. Since the character is closed mouthed, an open mouthed laugh didn't seem 
plausible. Also, the fact that it was silent and only made sounds when the viewer was within a certain range made it feel more like a trigger than an interaction. The solution is to have the piece continually hum, and change the volume and tone of the murmuring as the viewer approaches it.

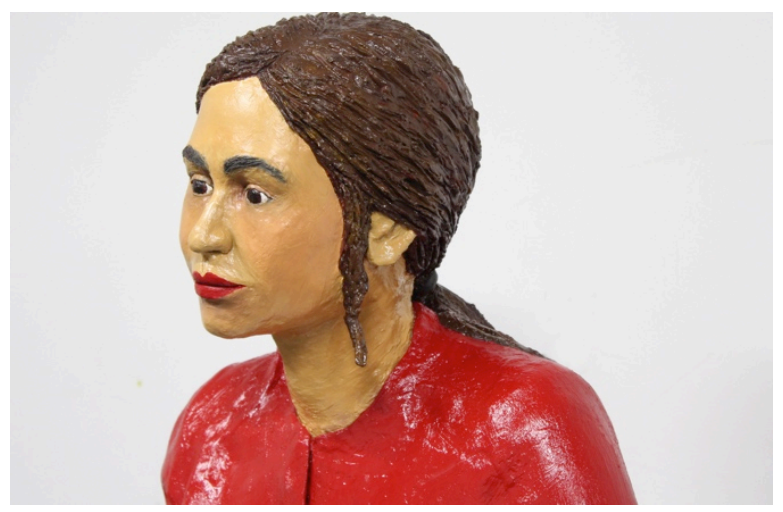

Figure 20: Sound-Bust Jofre (2014)

\section{Fuzzy Jofire}

Fuzzy Jofre never learned enough math to know that a minor infraction does not equal infinity.

Fuzzy Jofre is final figure constructed in this series of work and is therefore a culmination, of sorts, of what I have considered thus far. She breathes and turns her head; I felt these features were particularly 
successful in Monster Jofre and wanted to repeat them. Her face is cast from a silicone mold, which was created from the $3 \mathrm{~d}$ printed masks. So this is another copy of the copy. The various copies of the same face allowed me to examine the effects of materiality and of costume. Figure 21 shows a series of 4 heads whose faces were copied from the one shown on the left. Although they all exhibit some similarity to one another, it is also interesting to note how dramatically they differ considering that the facial forms on the right are all exact copies of the facial form on the left. While I experimented with casting several materials, for Fuzzy Jofre, I decided to use a particularly rough and grey paper pulp material.

Fuzzy Jofre, shown in figure 22, is an uncanny creation that is intended to challenge our notions of the feminine, so while she has feminine features (my face), and wears lipstick, she also has rough skin and hair all over her body. 


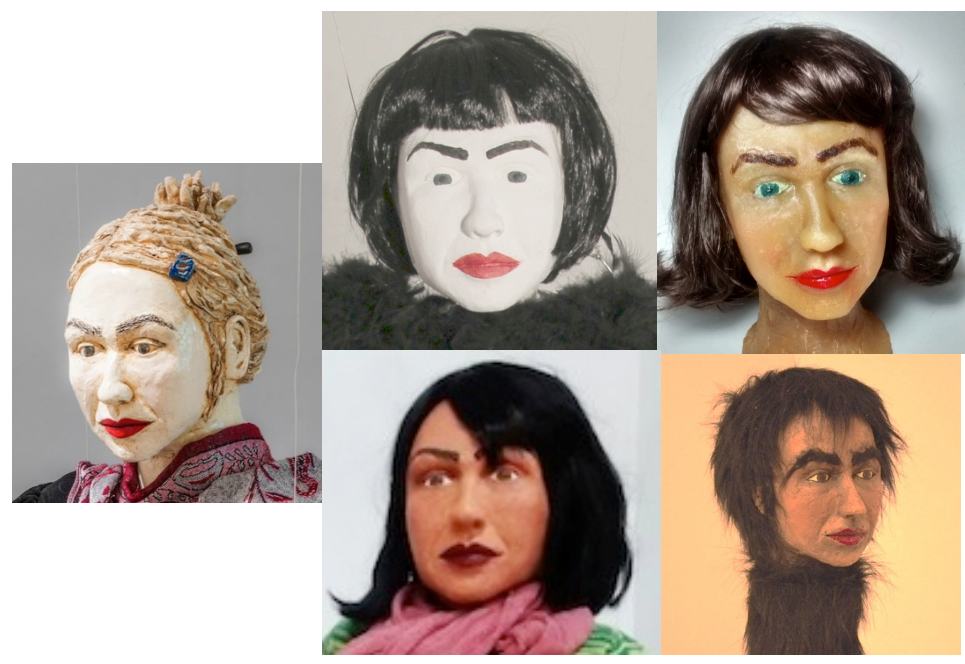

Figure 21: Left - ceramic self portrait. Right - faces copied from a digital scan of a ceramic self-portrait.

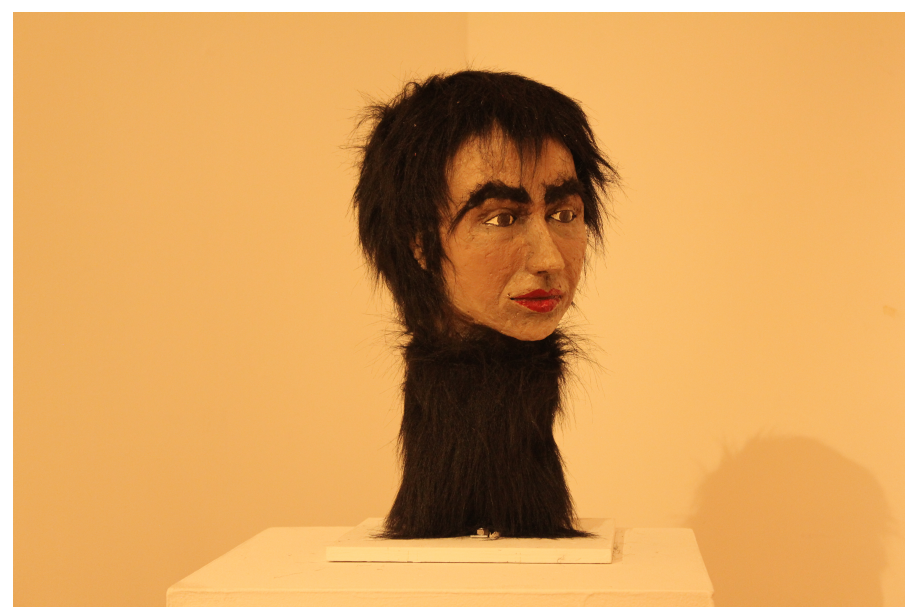

Figure 22: Fuzzy Jofre (2015)

\section{Summary of Processes}

The goal of this work was to use the illusion of a living presence and/or the relatability of the human form to evoke a visceral reaction that engages the 
viewer, and creates a playful experience. While I used the tools of electronic interactive art, I approached interactivity from a puppetry perspective, focusing on relatability and personal connection as the key driver for interaction. In each of these works, I use the uncanny to capture viewers' attention and compel them to engage with my works. The uncanny can evoke intrigue and wonder, or it can be a platform for humor and play. However, the uncanny can also evoke disgust, and even terror. To avoid the repulsive aspect of the uncanny, I was informed by the contemporary discourse in social robotics on the uncanny valley. I intend for my characters to be relatable, not frightening; and I hope to use the uncanny to create playful experiences supported by their relatability.

Each of the works in this collection is a result of exploring a slightly different aspect of the uncanny experience I seek to create. Suzana Jofre is the most puppet-like in appearance and in function; her relation to the viewer is as performer to spectator. Her human form, and her deviations from humanness create the uncanny sensation that captures the viewer's attention; but her campy persona and marionette strings invite humor and play. Joana Jofre is very similar to Suzana; their body forms were cast by the same method and their faces are both copies of the sculpture shown in figure 2. Building two entities from a similar basis led to an examination 
of how to differentiate them as individuals. Using the same rigid expressionless mask, I was able to create entirely different characters, each evoking a different mood by their different costumes, and their different poses. While Joana has the movability of a puppet, her body was stuffed with soft light materials, which made her more doll-like. Since Joana was lightweight and robust, I was able to easily mobilize her and place her into public situations to create interventions in which the unexpected presence of a life-sized humanoid doll evoked the uncanny.

Sound-Bust Jofre experiments with eliminating the puppetry element of my work, while Little Furry Beast explores what happens when the human form is abandoned. These two works explore reactivity as an element in creating the illusion of sentience, and they underline (for me) the importance of having a reactive element in creating an interactive experience. Little Furry Beast breathes faster as the viewer approaches, and Sound-Bust changes the sounds she makes as the viewer approaches.

Monster Jofre is a return to the puppetry aesthetic and to the human form, but it remains less puppet-like and less human-like than Suzana or Joana. This work took a distinctly robotic direction, with a body digitally constructed based on a wooden mannequin model. To evoke the 
uncanny, her head turns in reaction to the viewer, and she breathes. The success of her breathing motion compelled me to return to and add motion to Suzana and Joana.

My characters are all explicitly and intentionally female, in part because they are rough copies of me, and I am female. So from my point of view, it is the default gender, the neutral gender, and the universal gender, in the same way that the male gender is the default neutral and universal gender for the male creator. This question has come up often for me - why are they all female? I looked to see how Jim Henson may have addressed the question of his all (but two) male muppets and fraggles, but could not find a place where this question came up for him. It seems unlikely that his creatures were perceived as particularly unusual in their male-female balance, since male is typically perceived as neutral. So, it is interesting that people are compelled to question my characters' existence as females, and I hope this brings up some reflection on how we perceive and value female presence. 


\section{PART 4: CONCLUSIONS}

\section{Reflexive Evaluation}

I was hoping to achieve in each of these works a character and a presence; and I hope that each work can serve as a site for an uncanny experience. I think that for the most part, I succeeded with some variation. Sound-Bust Jofre might the one with the least character of them all, perhaps because of her bust shape or because her interactivity is limited to sound. Interestingly, this is the only one that wasn't built using puppetry techniques: its joints are not articulated, which supports my argument that the elements of puppetry in my work bolster its interactivity. The little furry beast is possibly the one that is least uncanny, perhaps because it is not human-like in any way. With the exception of the little furry beast, I stick with the human form because I think it connects more directly with viewers (it better facilitates the uncanny, for example), but also because I am specifically interested in reflecting, and in instigating reflection, on the human condition. However, the process work of creating non-human lifelike entities inspired the human-beast hybrids, Monster Jofre and fourlegged Suzana Jofre, that were so successful. 
Reviewing my project objectives:

- To create human-sized characters positioned within the space of the viewers.

- To disturb the boundary between the art and the viewer, and between subject and object.

- To create sculptural works that integrate elements, and methods from puppetry and from robotics, that reflect on the ideas of presence and the uncanny.

- To create uncanny but socially pleasurable experiences.

I achieved these objectives with my life-size figures and with my performances with them. However, perhaps the second point (to disturb the boundary between the art and viewer) is arguable when the works are viewed in the context of a gallery. This particular objective was achieved in my public play experiments with Joana, but it is entirely context specific. The boundary between the art and the viewer does not depend on the art object itself, but on how it is presented. When my work was presented in unexpected contexts, such as at the studio, it functioned well in both surprising the viewer and instigating playful moments. To push this direction further, I can show my work at restaurants and cafés instead of at art galleries. 
Addressing each of the research questions:

What elements push an object toward forming a sentient identity?

I found that the face was perhaps the most crucial element in creating the illusion of a character, even if it's an abstracted/obscured face, such as Monster Jofre's face, there seems to be some necessity for the viewer to connect to the eyes. The prosthetic eyes in Monster Jofre's face were a tremendous improvement over the painted eyes in terms of creating the illusion of sentience. The little furry beast's sensors, though they didn't look anything like eyes, were immediately taken to be eyes by viewers who wanted to play along with the illusion of sentience. In addition to needing at least a reference to eyes, I learned from studying puppetry that a subtle breathing motion is fundamental to maintaining the illusion of life; applying a subtle breathing motion to my sculptures successfully contributed to creating an illusion of lifelikeness. Making creatures that exhibited motion that was responsive to the viewer also contributed to the illusion of sentience.

What visual elements evoke empathy for an object? 
While some objects may have the capacity to elicit the sensation of 'cuteness', I realized in my experiments with Joana, that the degree of empathy a viewer can have for an object is for the most part dependent on the context. The same object in one context was mistreated (when left sitting at the Gladstone Hotel café), and in another context (when I was carefully taking her around Grange Park), she evoked deep empathy in a viewer that had done a lot of caregiving. Perhaps some animation and/or some interaction with the object is necessary to maintain an empathic bond with the viewer.

What pushes an object towards or away from the unpleasant uncanny valley?

From the disastrously awful intermediate form that Monster Jofre took, I saw immediately that a body with subtly incorrect proportions and a human face produces an unpleasant uncanny effect, as described by the uncanny valley. When I moved her away from being human, she became playfully uncanny rather than unpleasantly uncanny. The uncanny could be intriguing or even charming, but there is a specific domain of the uncanny that, as Mori advised (Mori 1970), is better avoided: the uncanny in that particular domain is simply unaesthetic (Hanson 2006). 


\section{Reflections on the final exhibition}

The final exhibition restored my confidence in my work. In the cluttered studio, the works started looking junky and for a long time, I wasn't able to see my work function as I had intended it. But seeing it installed in the gallery, I saw my work come alive (pun intended), and witnessed it functioning in the ways I intended. I was pleased with the results.

I was lucky to have been afforded the opportunity to present my work in a gallery that had a huge window front, and it was nice to see so many people, random passers-by, stop and look at my work. It seems my work really caught people's attention as they walked by, which was tremendously satisfying because perhaps the most general goal of any work of visual art is to capture a viewer's gaze. I think a big part of the immediate attention grab has to do with the fact that I'm using the human form, and our brains are wired to pay attention to the human form more keenly than any other. But I noticed that when I was at the window, cleaning it after the show, people walked by as if I wasn't really there. I'm a human form, but there's nothing uncanny about an ordinary lady cleaning a window. To catch people's attention, the human form must be altered in some way - fake humans stole many more gazes than a real 
human. This supports my argument that the uncanny is useful tool by which to capture attention and open a visual dialogue. What if I had an automaton cleaning the window instead? I will propose this at a window gallery. I think that's the next piece I want to make: the window washer. After I finish Fuzzy Jofre.

I never ended up making a body for Fuzzy Jofre for this show. I didn't want to rush it, and it was a good thing. It was good to take a step back and look at the body of work as a whole and see where she can fit into it. I want to continue making 'people' that aren't quite human. I found this not-totally-human direction was particularly successful with Monster Jofre and with 4-legged Suzana. Fuzzy Jofre, I think should continue to extend this development. She, like Monster, is a furry woman, but how else can she be uncanny? Her head looks nice mounted on her long furry neck. I wonder if perhaps she even needs a torso. What if she just had 4 legs, two arms, and that beautiful long neck? I am excited about the possibilities; the show and the defense have given me the confidence to open up my exploration. One feedback I was pleased to hear was that I had created my own stereotype. While I want to explore different forms and materials, I had worried that perhaps too many tangents would result in a disjointed un-unified body of work. It is flattering to hear that I have 
a recognizable style, and that I probably should be worried about many of the things that worry me in the art-making process. It was helpful to hear so much encouragement to follow my instincts, even the ones that the more sensible part of me might want to suppress.

One thing that I didn't explore in my thesis and in this body of work is my characters' potential role as personal companions. My principal supervisor had suggested placing one of the dolls in someone's home to see what would happen, and while I thought this was a great idea, I never did it and I regret this. I resisted doing this in part because I had some reservations about making dolls for personal use, as this came uncomfortably close to sex dolls, which was an avenue I wasn't interesting in exploring within the scope of this work. But I think I was in error to make this immediate association. Art functions on a personal level in people's homes on an everyday basis, and it would have been interesting how art that is also a humanoid character can function in the everyday context of people's homes. I think this was a missed opportunity, and it could have tied my interest in making art that functions outside the gallery context within the everyday, with my interest in social robotics. Now that I am seeking storage space for my work, this could present an opportunity to try this - to let someone live with one of my people for a few months. 
Some people that visited the gallery expressed a desire to have them at home. Again, the show gave me the confidence to move my work forward in ways that were previously inhibited.

One thing I realized that my work does that I hadn't reflected about extensively until the show is that it fuses craft (dolls and puppets) with new media (mechanical motion and electronic interactivity). Two art history graduate students that came to view the work at the gallery pointed this out. They were very excited by my work as they were in the midst of writing a paper about the integration of new media with crafts, and they may include me in their paper as an example or case study.

\section{Future Directions}

In many ways I feel as if I'm trying to wrap things up just as I'm getting started, so one obvious direction in which this work could continue is to build more of these 'people', perhaps amounting to a more cohesive cast of characters, or a community of creatures. There are two directions in which I want to continue this work: 1) to build more monstrous humanoid creatures, and 2) to place my humanoid sculptures in unexpected contexts such as restaurants or coffee shops or washing a gallery window. The latter would perhaps require more humanoid and less monstrous creatures, though it would be interesting to experiment with a range. 
In continuing to create characters, I would continue to gender them female, largely as a response to the fact that most artistic fictional creatures (see for example muppets, fraggles, or smurfs) are explicitly gendered male; I hope to set some balance by creating a world or two where the female form is the default, the neutral. I would also continue to expand my repertoire of creatures into the non-human. Monster Jofre's success was in large part because of her departure from human-ness, and Suzana Jofre became more visually interesting when she acquired a second pair of legs.

While I enjoyed the serendipitous journey through which Monster and Suzana were created, I'm curious about finding more systematic methods by which to generate monstrous characters. I have recently become very fascinated with questions about how to better understand data through visual or physical representation. So, it occurred to me that I could use data to design the body forms. I could build body forms with proportions in relation to how much each body part is used, thus designing characters based on data. For example, if someone spends most of their time at a computer, maybe their eyes and fingers are disproportionately large. 
Someone who works a lot with their hands may have many hands or very large hands.

A series of multiple characters could be used to create narrative installations, or performances. Narrative is an aspect of puppetry that I did not fully integrate into my work, and this can certainly be developed through blogging. One way in which to develop a natural narrative is to track and document one character's public interventions, and to use the public's interactions it to shape the character's story. The public interventions done with Joana show some promise in this direction. The committee at my defense suggested I need to let go of the characters a little - let them develop on their own. I expressed concern that perhaps she could get damaged, and the possibility was presented to me that maybe she is mortal. Indeed, why not?

Another means by which to integrate narrative in my work is by means of theatrical collaborations. The creatures I create can physically function as puppets; so a theatrical collaboration is certainly a possibility in future work. 
As I continue to make more creatures, I want to also think of how they can function in groups, beyond creating narrative scenarios. Multiples have the potential to function subversively. What if these characters were used to sit in for workers on strike? How would authorities react to a picket line of these characters? Would I be able to use these body forms to stand in at a protest for people who can't afford to travel or take time off work, or for those afraid of police confrontation? Would I be able to create a symbolic protest with a mass of these characters? In this thesis work, I discussed how puppetry is used as a tool for political protest and for community building, but I did not integrate these aspects of puppetry into my practice. I hold this up as a challenge to myself.

Could I use groupings of these characters, to physically represent data about humans? I have argued in this thesis that the physically rendered life-sized figurative forms embody the uncanny and provoke a visceral reaction that emotionally engages the viewer, so I speculate that using them to represent data may lead to a better emotional understanding of political issues that involve human lives. Ten thousand body forms evoke an entirely different feeling than ten thousand cubes. 
One avenue that I left completely unexplored in my thesis work is the use of emotional expressions; they may merit further investigation. I've been working with neutral faces so far, and left the dimension of facial expression completely unexplored. Emotional expressions may increase the intensity of the psychological interactivity of the work, but it can also limit the scope of their narrative. I chose to stay with neutral expressions in the tradition of puppetry, to make my faces versatile for a range of installations and situations. But now I'm curious about how emotional expressions could change the nature of the interaction with my work.

The scope of my theoretical explorations in this thesis was quite large, and it may take many years for me to explore all of these considerations in my practice. But I may not need to explore all these possibilities within my own practice to combine all of these ideas into an aesthetic experience. This thesis could be the theoretical foundation for a curatorial experiment that combines the works of sculptors, puppeteers, and scientists into a single exhibition. It may be interesting to see how these topics are tackled from different disciplinary perspectives and how they can be integrated into a single interdisciplinary exhibit. 


\section{Summary and Conclusions}

In this work, I set out to explore the illusion of presence, the uncanny, and, to some extent, the creation of character. The investigation started with a literature review that included interactive arts, figurative sculpture, puppetry, and social robotics. Each of these disciplines, despite being diverse from one another, addresses the uncanny and the sensation of presence. Studies in humanoid robotics defined a regime within the uncanny, known as the uncanny valley (Mori 1970), where the illusion of lifelikeness provokes feelings of discomfort. However, it is possible to avoid this regime of the uncanny with aesthetic considerations (Hanson 2006). Furthermore, the uncanny is not always entirely negative; the uncanny could be intriguing, thought provoking, or even charming. A look at the history of puppetry and a survey of some figurative sculptures reveals that uncanny objects with presence open up spaces for sociopolitical criticism and arts-based inquiry.

In my practice, I used a reflexive methodology to produce a series of objects in which I evoked the illusion of a living presence, and generated a site for uncanny experiences. I found that the illusion of presence was invoked by objects of human scale with anatomically correct proportions, by objects with autonomous motion, and by objects that mechanically 
respond to the viewer. Furthermore, my characters, despite all having a rigid neutral facial expression, each have a personality that was expressed through their materiality, through their costumes, through their limited actions, and through how I performed with them.

My sculptures were created with a Camp sensibility. Camp's naïve outlandishness can cause discomfort, as does the sense of the uncanny, and here in this work, I have amalgamated the two by examining the uncanny with a Camp sensibility. The result was a series of quirky objects that evoke presence or character.

This research-creation work proposes a way in which to render the white cube gallery less sterile and more inviting, using elements from puppetry practice, seasoned lightly with Camp. The common thread that I use to tie robotics to puppetry to sculpture is the human figure, and my approach to building the figurative form is centered on establishing a connection to the viewer. Relatability is a key element of my works, and to achieve this, I utilized the performativity of puppetry along with an awareness of the discourse and issues in social robotics. This fusion of disciplines allowed me to find a new way to engage people with sculptural works, with a psychological interactivity that is inspired by the personability of puppetry 
rather than a physical interactivity prodded by prompts. I have been able to use my humanoid sculptures to create playful interactive experiences, as shown in the documentation posted on the wall. Many of these experiences hinge on the uncanny - they often start with a startled utterance that breaks into a laugh. The uncanny effect in this case is provoked by the illusion of presence, and in performance, the illusion is accepted and sustained through deliberate acts of play.

The contribution to sculpture offered by this work is an integration of puppetry and robotics into the discipline so as to introduce a new way of seeing sculptural objects, not just as forms that interact with space, but as personalities that interact with people. 


\section{Bibliography and Works Cited}

Adorno, T.W. and Max Horkheimer "The Concept of Enlightenment" in Dialectic of enlightenment. London: Verso, 1997.

Alvesson, Mats, and Kaj Sköldberg. Reflexive methodology: New vistas for qualitative research. Sage, 2009.

Arkowitz, Hal and Scott O. Lilienfeld Is Depression Just Bad Chemistry?

Scientific American, Volume 25, Issue 2 Mar 1, 2014

Becker-Asano, Christian, Kohei Ogawa, Shuichi Nishio, and Hiroshi Ishiguro. "Exploring the uncanny valley with Geminoid HI-1 in a realworld application." InProceedings of IADIS International Conference Interfaces and Human Computer Interaction, pp. 121-128. 2010.

Bell, John. "The Nineteenth Annual Domestic Resurrection Circus." Theater Vol. 18, no. 3 (1987): 35-42.

Bell, John. "Uprising of the Beast: An Interview with Peter Schumann." Theater Vol. 25, no. 1 (1994): 32-43.

Bell, John. "The End of Our Domestic Resurrection Circus: Bread and Puppet Theater and Counterculture Performance in the 1990s." TDR/The Drama Review Vol. 43, no. 3 (1999): 62-80.

Bickmore, T.W. and R. W. Picard. Establishing and maintaining long-term human-computer relationships. ACM Trans. Comput.-Hum. Interact., June 2005 .

Biggs, Michael AR, and Daniela Büchler. "Rigor and practice-based research."Design issues 23, no. 3 (2007): 62-69.

Breazeal, C. Emotion and sociable humanoid robots. Int. J. Hum.-Comput. Stud., 59:119-155, July 2003.

Breazeal, Cynthia, and Rodney Brooks. "Robot emotion: A functional perspective." Who needs emotions (2005): 271-310. 
Breazeal, Cynthia. "Apparatus and methods for providing a persistent companion device." U.S. Patent Application 14/210,037, filed March 13, 2014 .

Brecht, Stephen. "Peter Shumann's Bread \& Puppet Theatre.” The Drama Review (TDR), Vol 14, No. 3 (1970): 44-46.

Brecht, Stephen. "A Poor Theatre." TDR/The Drama Review, Vol 14, No. 3 (1970): 89-90.

Bush, Martin H. Duane Hanson. Wichita, Kansas: Wichita State University, 1976.

Butler, Judith. Bodies That Matter: On the Discursive Limits of "Sex". New York: Routledge, 1993. Pg 1-23.

Butler, Judith. "Imitation and Gender Insubordination." Cultural theory and popular culture: A reader (2006).

Castro-González, Álvaro, María Malfaz, J. F. Gorostiza, and Miguel A. Salichs. "Learning Behaviors by an Autonomous Social Robot with Motivations."Cybernetics and Systems 45, no. 7 (2014): 568-598.

Cavell, Stanley. "The uncanniness of the ordinary." In Quest of the Ordinary: lines of skepticism and romanticism (1988): 153-78.

Cherouvim, Georgios. 2014. "Debate | ch3." ch3.gr.

http://ch3.gr/2014/debate/accessed March 4, 2015.

Coradeschi, Silvia, Amadeo Cesta, Gabriella Cortellessa, Luca Coraci, C. Galindo, Javier Gonzalez, Lars Karlsson et al. "GiraffPlus: A System for Monitoring Activities and Physiological Parameters and Promoting Social Interaction for Elderly." In Human-Computer Systems Interaction: Backgrounds and Applications 3, pp. 261-271. Springer International Publishing, 2014.

Daichendt, G. James. Artist scholar: Reflections on writing and research. Intellect Books, 2011.

Damasio, Antonio R. Descartes' error: Emotion, rationality and the human brain. New York: Putnam, 1994. 
De Freitas, Nancy. "Towards a definition of studio documentation: working tool and transparent record." Working papers in art and design 2 (2002): 1-10.

Deleuze, Gilles and Felix Guattari. "November 28, 1947: How Do You Make Yourself a Body without Organs?" in A Thousand Plateaus. A thousand plateaus: Capitalism and schizophrenia. Vol. 2. Minneapolis: U of Minnesota Press, 1987.

Dewey, John. [1934] 1980. Art as Experience. Reprint. New York: Wideview/Perigree

Donnel-Kotrozo, Carol. "Material Illusion." The Journal of Aesthetics and Art Criticism. 42 (1984): 277-282.

Doss, Erika. "Duane Hanson's Woman Eating." American Art. 20 (2006): 9-12

Ekman, Paul, E. Richard Sorenson, and Wallace V. Friesen. "Pan-cultural elements in facial displays of emotion." Science 164, no. 3875 (1969): 8688.

Ekman, Paul, and Wallace V. Friesen. "A new pan-cultural facial expression of emotion." Motivation and emotion 10, no. 2 (1986): 159168.

Etcoff, N. Survival of the Prettiest. New York: Anchor, 2000.

Falk, Florence. "Bread and Puppet: Domestic Resurrection Circus." Performing Arts Journal Vol. 2, no. 1 (1977): 19-30.

Fitzpatrick, Michael. "The hyper-real robots that will replace receptionists, pop stars... and even sex dolls: Unnervingly human androids coming to a future very near you" MailOnline Nov. 20, 2014 http://www.dailymail.co.uk/news/article-2841273/The-hyper-realrobots-replace-receptionists-pop-stars-sex-dolls-Unnervingly-humanandroids-coming-future-near-you.html

Foster, Hal. "Armor Fou." October 56 (1991): 65-97.

Freeland, Cynthia. "Portraits in Painting and Photography."Philosophical Studies: An International Journal for Philosophy in the AnalyticTradition, Vol. 
135, No. 1, Proceedings of the Thirty-Seventh Oberlin Colloquium in Philosophy: Aesthetics (Aug., 2007), pp. 95-109

Freud, Sigmund. "The Uncanny.” (1919) Trans. by Alix Strachey. First published in Imago, Bd. V., 1919; reprinted in Sammlung, Fünfte Folge.

Germeraad, Gert "Rationality, Intuition and Emotion - Exploring an Artistic Process" Journal for Artistic Research. 3 (2013)

Giraff Plus. 2014. "Giraff Plus" griraffplus.edu http://www.giraffplus.eu/ accessed March 4, 2015.

Gould, James L. Ethology: The mechanisms and evolution of behavior. New York: WW Norton, 1982.

Grant, Catherine. "Bellmer's Legs: Adolescent Pornography and Uncanny Eroticism in the Photographs of Hans Bellmer and Anna Gaskell." Papers of Surrealism 8 (2010): 1-20.

Grocot, Lisa. "Speculation, Serendipity and Studio Anybody." In Design Research: Methods and Perspectives, edited by Brenda Laurel, 83-94. Cambridge, MA: MIT Press, 2003

Gross, Kenneth. Puppet: An essay on uncanny life. University of Chicago Press, 2011.

Grow, Kory. "Life-Size Lady Gaga Dolls Coming Soon" Rolling Stone Magazine, December 2, 2013, accessed March 20, 2014, http://www.rollingstone.com/music/news/life-size-lady-gaga-dollscoming-Soon-20131202

Harris, Daniel. "The Aesthetic of Drag." Salmagundi No. 108 (1995): 6274

Hanson, David, Andrew Olney, Steve Prilliman, Eric Mathews, Marge Zielke, Derek Hammons, Raul Fernandez, and Harry Stephanou. "Upending the uncanny valley." In Proceedings of the national conference on artificial intelligence, vol. 20, no. 4, p. 1728. Menlo Park, CA; Cambridge, MA; London; AAAI Press; MIT Press; 1999, 2005. 
Hanson, David. "Exploring the aesthetic range for humanoid robots." InProceedings of the ICCS/CogSci-2006 long symposium: Toward social mechanisms of android science, pp. 39-42. 2006.

Heintz, Suzanne. 2014. "Suzanne Heintz - Life Once Removed" suzanneheintz.com http://suzanneheintz.com/life-once-removed/ accessed March 4, 2015.

Hourahan, Shelagh. "The Magic and Theatre of Ana Maria Pacheco." Women's Art Magazine. 45 (1992): 18-19.

Ishiguro, Hiroshi. "Interactive humanoids and androids as ideal interfaces for humans." In Proceedings of the 11th international conference on Intelligent user interfaces, pp. 2-9. ACM, 2006.

Ishiguro, Hiroshi. 2007. “Geminoid” gemoid.jp http://www.geminoid.jp/projects/kibans/overview.html accessed March 4, 2015 .

Jentsch, Ernst. "On the psychology of the uncanny (1906) 1." Angelaki: Journal of the Theoretical Humanities 2, no. 1 (1997): 7-16.

Jibo. 2015. “JIBO.” jibo.com http://jibo.com accessed March 4, 2015.

Karlsruhe Institute of Technology. 2015 "KIT - HISResearch - Humanoids - Key Research Areas - Integrated Humanoid Platform - ARMAR Family" Karlsruhe Institute of Technology.

http://his.anthropomatik.kit.edu/english/241.php accessed March 4, 2015

Kerstin Sophie Haring, Yoshio Matsumoto, and Katsumi Watanabe "How Do People Perceive and Trust a Lifelike Robot" Proceedings of the World Congress on Engineering and Computer Science 2013 Vol I, WCECS 2013, 23-25 October, 2013, San Francisco, USA

Kidd, Cory D., Will Taggart, and Sherry Turkle. "A sociable robot to encourage social interaction among the elderly." In Robotics and Automation, 2006. ICRA 2006. Proceedings 2006 IEEE International Conference on, pp. 3972-3976. IEEE, 2006.

Krauss, Rosalind. "The photographic Conditions of Surrealism." October 19 (1981): 3-34. 
Krauss, Rosalind. "Corpus delicti." October 33 (1985): 31-72.

Kourilsky, Françoise. "Dada and Circus:" Peter Schumann's Bread and Puppet Theatre"." TDR/The Drama Review. Vol. 18, no. 1 (1974): 104109.

Le Guin, Charles A. "The Language of Portraiture." Biography, Vol. 6, No. 4 (Fall 1983), pp. 333-341

Leshnoff, Susan K. "Art, Ambiguity and Critical Thinking". Art Education. 48 (1995): 51-56.

Lichtenstein, Thérèse, Behind Closed Doors: The Art of Hans

Bellmer; [this Book Complements the Exhibition" Behind Closed Doors: The Art of Hans Bellmer", curated by Therese Lichtenstein for the International Center of Photography, New York, March 29-June 10, 2001]. Berkeley: Univ of California Press, 2001.

Low, Philip, J. Panksepp, D. Reiss, D. Edelman, B. Van Swinderen, P. Low, and C. Koch. "The Cambridge declaration on consciousness." In Francis crick memorial conference on consciousness in human and non-human animals. University of Cambridge, Cambridge, England. Retrieved from http://fcmconference. org/img/CambridgeDeclarationOnConsciousness. pdf. 2012.

MacDorman, Karl F. "Subjective ratings of robot video clips for human likeness, familiarity, and eeriness: An exploration of the uncanny valley." In ICCS/CogSci-2006 long symposium: Toward social mechanisms of android science, pp. 26-29. 2006.

MacDorman, Karl F., and Hiroshi Ishiguro. "The uncanny advantage of using androids in cognitive and social science research." Interaction Studies 7, no. 3 (2006): 297-337.

Martin, David F. "On Portraiture: Some Distinctions" The Journal of Aesthetics and Art Criticism, Vol. 20, No. 1 (Autumn, 1961), pp. 61-72

Marynowsky, Wade. "The Uncanny Automaton." Leonardo 45, no. 5 (2012): 482-483.

Mattern, Mark. "John Dewey, art and public life." The Journal of Politics 61, no. 01 (1999): 54-75. 
Mcauliffe, Kathleen. "How Your Cat Is Making You Crazy", The Atlantic, March 2012

Meschke, Michael, and Margareta Sörenson. In search of aesthetics for the puppet theatre. Indira Gandhi national centre for the arts, 1992.

Mo, Charles L. Splendors of the New World: Spanish Colonial Masterworks from the Viceroyalty of Peru. Mint Museum of Art, 1992.

Mori, M. (1970/2012). The uncanny valley (K. F. MacDorman \& N. Kageki, Trans.). IEEE Robotics \& Automation Magazine, 19(2), 98-100.

Nishio, Shuichi, Tetsuya Watanabe, Kohei Ogawa, and Hiroshi Ishiguro. "Body ownership transfer to teleoperated android robot." In Social Robotics, pp. 398-407. Springer Berlin Heidelberg, 2012.

Ortony, A., G. L. Clore., and A. Collins Cambridge University Press: Cambridge (1988). The cognitive structure of emotions.

PARO Robots Inc. "PARO the therapeutic robot" (http://www.parorobots.com) accessed March 4, 2015

Philpott, Rachel. "Engineering Opportunities for Originality and Invention: The importance of playful making as developmental method in practice-led design research.” Studies in Material Thinking. Vol 9, Paper 5 (2013): 1-16.

The Puppetistas. "A Puppetista Manifesto" wafreepress.org. http://wafreepress.org/50/Puppetista.htm accessed March 4, 2015

Plotnik, Joshua M., Frans BM De Waal, and Diana Reiss. "Self-recognition in an Asian elephant." Proceedings of the National Academy of Sciences 103, no. 45 (2006): 17053-17057.

Rauscher, Morgan. 2013. "Zeugen V2 | Morgan Rauscher." morganrauscher.com. http://morganrauscher.com/morganrauscher/portfolio/zeugen-v2/ accessed March 4, 2015 
Reiss, Diana, and Lori Marino. "Mirror self-recognition in the bottlenose dolphin: A case of cognitive convergence." Proceedings of the National Academy of Sciences 98, no. 10 (2001): 5937-5942.

Robins, B., Amirabdollahian, F. \& Dautenhahn, K., 2013. Investigating Child-Robot Tactile Interactions: A Taxonomical Classification of Tactile Behaviour of Children with Autism Towards a Humanoid Robot. In ACHI 2013. The Sixth International Conference on Advances in ComputerHuman Interactions. Nice, France, pp. 89-94.

Robins, B., K. Dautenhahn, R. te Boekhorst, C. L. Nehaniv (2008) Behaviour Delay and Robot Expressiveness in Child-Robot Interactions: A User Study on Interaction Kinesics. Proc. ACM/IEEE 3rd International Conference on Human-Robot Interaction (HRI 2008). 12-15 March 2008, Amsterdam, the Netherlands.

Robotics Lab Universidad Carlos II Madrid. 2015. "Maggie | Robotic Lab - Where Technology Happens." Robotics Lab Universidad Carlos II Madrid. (http://roboticslab.uc3m.es/roboticslab/robot/maggie) accessed March 4, 2015.

Saunders, Linda. “Ana Maria Pacheco” Modern Painters. 3 (1990): 76-77

Schumann, Fritz. 2014 “The Valley of Dolls.” Vimeo video, 6:30, March 2014. https://vimeo.com/92453765

Schumann, Peter. "Bread and Puppets" TDR/The Drama Review, Vol 14, No. 3 (1970): 35 .

Schumann, Peter. "The Radicality of the Puppet Theatre." TDR/The Drama Review, Vol 35, no. 4 (1991): 75-83.

Shuman, Peter. "What, At the End of This Century, Is the Situation of Puppets and Performing Objects?" in Puppets, masks, and performing objects. Bell, John, ed. MIT Press, 1999.

Scrivener, Stephen. "The art object does not embody a form of knowledge."Working papers in art and design 2 (2002).

Smith, Marquand. "Just what is it that makes today's Hans Bellmer so different, so appealing?." Art History 26, no. 1 (2003): 100-105. 
Sontag, Susan. "Notes on camp." Camp: Queer aesthetics and the performing subject (1964): 53-65.

Stuby, Tamara. "Dark Night under a bright light. Ana Maria Pacheco's Dark Night of the Soul." Third Text. 50 (2000): 114-116

Sullivan, Graeme. "Research acts in art practice." Studies in Art Education(2006): 19-35.

Sullivan, Graeme, ed. Art practice as research: Inquiry in visual arts. Sage, 2010.

Szirtes, George. Exercise of Power: The Art of Ana Maria Pacheco. Burlington,Vermont: Lund-Humphries, 2001.

Ribeiro, Tiago, and Ana Paiva. "The illusion of robotic life: principles and practices of animation for robots." In Proceedings of the seventh annual ACM/IEEE international conference on Human-Robot Interaction, pp. 383-390. ACM, 2012.

Steunebrink, Bas R., Mehdi Dastani, and John-Jules Ch Meyer. "The OCC model revisited." In Proceedings of the 4th Workshop on Emotion and Computing, vol. 65, pp. 2047-2056. 2009.

Taylor, Sue. "Hans Bellmer in The Art Institute of Chicago: The Wandering Libido and the Hysterical Body." Art Institute of Chicago Museum Studies 22, no. 2 (1996): 151-199.

University of Hertfordshire. 2015. "Kaspar, The Social Robot." University of Hertfordshire. http://www.herts.ac.uk/kaspar/the-social-robot accessed March 4, 2015.

Varnedoe, Kirk. Duane Hanson. New York: Harry N. Abrams. Inc, 1985

Von Kleist, Heinrich. "On the Marionette Theater." (1810).

Wada, Kazuyoshi, Takanori Shibata, Tomoko Saito, Kayoko Sakamoto, and Kazuo Tanie. "Psychological and social effects of one year robot assisted activity on elderly people at a health service facility for the aged." In Robotics and Automation, 2005. ICRA 2005. Proceedings of the 2005 IEEE International Conference on, pp. 2785-2790. IEEE, 2005. 
Wolchover, Natalie. "A New Physics Theory of Life", Quanta Magazine, January 22, 2014

Zamir, Tzachi. "Puppets", published in Critical Inquiry Vol. 36, No. 3 (Spring 2010), pp386-409 